\title{
An Individual Patient's "Body" on Chips-How Organismoid Theory Can Translate Into Your Personal Precision Therapy Approach
}

\begin{abstract}
Uwe Marx ${ }^{1,2 \star}$, Enrico Accastelli ${ }^{2}$, Rhiannon David ${ }^{3}$, Hendrik Erfurth ${ }^{2}$, Leopold Koenig ${ }^{2}$, Roland Lauster ${ }^{1}$, Anja Patricia Ramme ${ }^{2}$, Petra Reinke ${ }^{4,5}$, Hans-Dieter Volk ${ }^{5}$, Annika Winter ${ }^{2}$ and Eva-Maria Dehne ${ }^{2}$
\end{abstract}

${ }^{1}$ Department of Medical Biotechnology, Institute of Biotechnology, Technische Universität Berlin, Berlin, Germany, ${ }^{2}$ TissUse GmbH, Berlin, Germany, ${ }^{3}$ Functional and Mechanistic Safety, Clinical Pharmacology \& Safety Sciences, R\&D, AstraZeneca, Cambridge, United Kingdom, ${ }^{4}$ Berlin Center for Advanced Therapies, Charité-Universitätsmedizin Berlin, Berlin, Germany, ${ }^{5}$ BIH-Center for Regenerative Therapies, Berlin Institute of Health, Charité-Universitätsmedizin Berlin, Berlin, Germany

\section{OPEN ACCESS}

Edited by: Victoria Bunik,

Lomonosov Moscow State

University, Russia

Reviewed by:

Ekaterina Kolesanova, Institute of Biomedical

Chemistry, Russia

Reiner Wiest,

University Children's Hospital

Bern, Switzerland

*Correspondence:

Uwe Marx

uwe.marx@tissuse.com

Specialty section:

This article was submitted to Translational Medicine,

a section of the journal

Frontiers in Medicine

Received: 22 June 2021 Accepted: 16 August 2021 Published: 13 September 2021

Citation:

Marx U, Accastelli E, David R, Erfurth $H$, Koenig L, Lauster $R$, Ramme AP, Reinke P, Volk H-D, Winter $A$ and Dehne E-M (2021) An

Individual Patient's "Body" on Chips-How Organismoid Theory Can Translate Into Your Personal Precision Therapy Approach.

Front. Med. 8:728866. doi: 10.3389/fmed.2021.728866
The first concepts for reproducing human systemic organismal biology in vitro were developed over 12 years ago. Such concepts, then called human- or body-on-a-chip, claimed that microphysiological systems would become the relevant technology platform emulating the physiology and morphology of human organisms at the smallest biologically acceptable scale in vitro and, therefore, would enable the selection of personalized therapies for any patient at unprecedented precision. Meanwhile, the first human organoids-stem cell-derived complex three-dimensional organ models that expand and self-organize in vitro-have proven that in vitro self-assembly of minute premature human organ-like structures is feasible, once the respective stimuli of ontogenesis are provided to human stem cells. Such premature organoids can precisely reflect a number of distinct physiological and pathophysiological features of their respective counterparts in the human body. We now develop the human-on-a-chip concepts of the past into an organismoid theory. We describe the current concept and principles to create a series of organismoids - minute, mindless and emotion-free physiological in vitro equivalents of an individual's mature human body - by an artificially short process of morphogenetic self-assembly mimicking an individual's ontogenesis from egg cell to sexually mature organism. Subsequently, we provide the concept and principles to maintain such an individual's set of organismoids at a self-sustained functional healthy homeostasis over very long time frames in vitro. Principles how to perturb a subset of healthy organismoids by means of the natural or artificial induction of diseases are enrolled to emulate an individual's disease process. Finally, we discuss using such series of healthy and perturbed organismoids in predictively selecting, scheduling and dosing an individual patient's personalized therapy or medicine precisely. The potential impact of the organismoid theory on our healthcare system generally and the rapid adoption of disruptive personalized T-cell therapies particularly is highlighted.

Keywords: organismoid, organ-on-chip, microphysiological systems, real world data, immune-oncology, advanced therapies, organoid, patient-on-chip 


\section{INTRODUCTION TO THE ORGANISMOID THEORY}

A human individual's lifespan is characterized by phases of development (ontogenesis) and functional maintenance (adulthood) of the physiology and morphology of the human body and a lifelong sociogenesis of an individual's soul and mind in a bidirectional person to population context (1), schematically illustrated in Figure 1A.

Sociogenesis is linked intrinsically to the morphological size and architecture of the human brain defined-consisting of around 86 billion neurons and a roughly equal number of nonneuronal cells (2) that are highly interconnected and clustered to process, integrate and coordinate the information it receives from the sense organs (3) - and its interconnections with the rest of the body. The physiology of the mature human body follows a simple evolutionary, selected building plan where form follows function. Back in 2007, we drew attention to the fact "[...] that almost all organs and systems are built up by multiple, identical, functionally self-reliant, structural units [...] ranging from several cell layers to a few millimeters. Due to distinguished functionality, a high degree of self-reliance and multiplicity of such structural units within the respective organ, their reactivity pattern to drugs and biologics seem representative of the whole organ. Nature created these small, but sophisticated, biological structures to realize most prominent functions of organs and systems. The multiplication of these structures within a given organ is Nature's risk-management tool to prevent the total loss of functionality during partial organ damage. In evolutionary terms, however, this concept has allowed the easy adjustment of organ size and shape to the needs of a given species (e.g., liver in mice and men), while still using almost the same master plan [... ]" (4). In 2012, this knowledge, combined with progress in the development of microphysiological systems (MPS), provided the basis for the first conceptual visions of emulating human bodies at the smallest biologically acceptable scale on biochips (5-7). At that time, we introduced the concept of a "man-on-a-chip" at a downscale factor of 100,000 . We illustrated the functional units of the major human organs and briefly described the downscale principle (5). This was the starting point for developing a theory of the establishment of minute mindless and emotion-free physiological in vitro equivalents of an individual's human body, which we now call organismoids. Different terminologies, such as human-on-a-chip, body-on-a-chip, or universal physiological template, have been used in the past for organismoids, but it is common sense among the MPS community that the targeted organismal homeostasis can be achieved by combining the prime organ equivalents from at least the following 10 human systems: circulatory, endocrine, gastrointestinal, immune, integumentary, musculoskeletal, nervous, reproductive, respiratory and urinary.

\footnotetext{
Abbreviations: 3D, three-dimensional; ASCs, adult stem cells; BBB, blood-brain barrier; CAR-T, bhimeric antigen receptor T; ESCs, embryonic stem cells; hESCs, human embryonic stem cells; hiPSCs, human induced pluripotent stem cells; iPSCs, induced pluripotent stem cells; MPS, microphysiological systems; NMJs, neuromuscular junctions; PDX, patient-derived xenograft; PSCs, pluripotent stem cells; SGLT2, sodium glucose transporter 2; TEER, transepithelial electrical resistance; USD, United States dollar.
}

A chip-based system interconnecting these organ models will compose a minimal organismal equivalent and the MPS community forecasts at least another decade to establish such functional organismoids on chips $(8,9)$.

These can be used to emulate an individual patient's disease and healthy state, as illustrated in Figure 1B, therewith enabling a precise selection of the right medicine or therapy and the most efficacious exposure regime for each patient. In addition to this use for precision medicine approaches organismoids from selected cohorts of patients can further be used to conduct clinical trials on chips. Their position within the current landscape of cell models regarding their potential to emulate human physiology was illustrated in 2018 by the Investigative Toxicology Leaders Forum, which brought together representatives from 14 European pharmaceutical companies (Figure 2) (10).

The organismoid theory is based on two chronologically interrelated concepts, each with three principles for implementation. The concept of in vitro ontogenesis of an individual's organismoids relies on the principles of (i) (induced pluripotent) stem cell-based formation of premature organoids of an individual body in vitro; (ii) physiology-based integration of the relevant type and ratio/numbers of such premature organoids into premature self-sustained organismoids through whole blood perfusion and innervation, applying on-chip MPS; and the (iii) completion of in vitro ontogenesis toward healthy mature organismoids (emulating the adult stage) by organoid on-chip cross talk and accelerated exposure to ontogenic stimuli.

Subsequently, the concept of emulating the process of disease and healing of an individual patient using his/her organismoids on chips follows the principles of (i) induction of a disease in organismoids by natural disease processes or the transmission of pathogens or diseased tissues derived from the patient; (ii) the mimicry of a human clinical trial with a large number of patients by a trial with the equivalent number of healthy and diseased organismoids of one single patient; and (iii) the precise selection of the right medicine or therapy and the most efficacious exposure regime for each individual patient.

In this paper, we take you through the concepts and principles of organismoid theory, underpin the most important aspects with actual results and observations, describe its disruptive potential for our healthcare system and provide an outlook on possible approaches to a final proof of the theory.

\section{WHAT DID STEM CELL- AND PATIENT-DERIVED ORGANOIDS TEACH US?}

Deciphering the biochemical and biophysical cues leading to tissue-specific morphogenesis and organogenesis in vivo has fascinated scientists for over a century. Their studies were confined to classical cell culture and animal models for lack of more physiologically relevant test systems. These models have vastly enhanced our basic understanding of cellular function and disease mechanisms. However, translation of results to the human situation has become a major bottleneck. Recent 


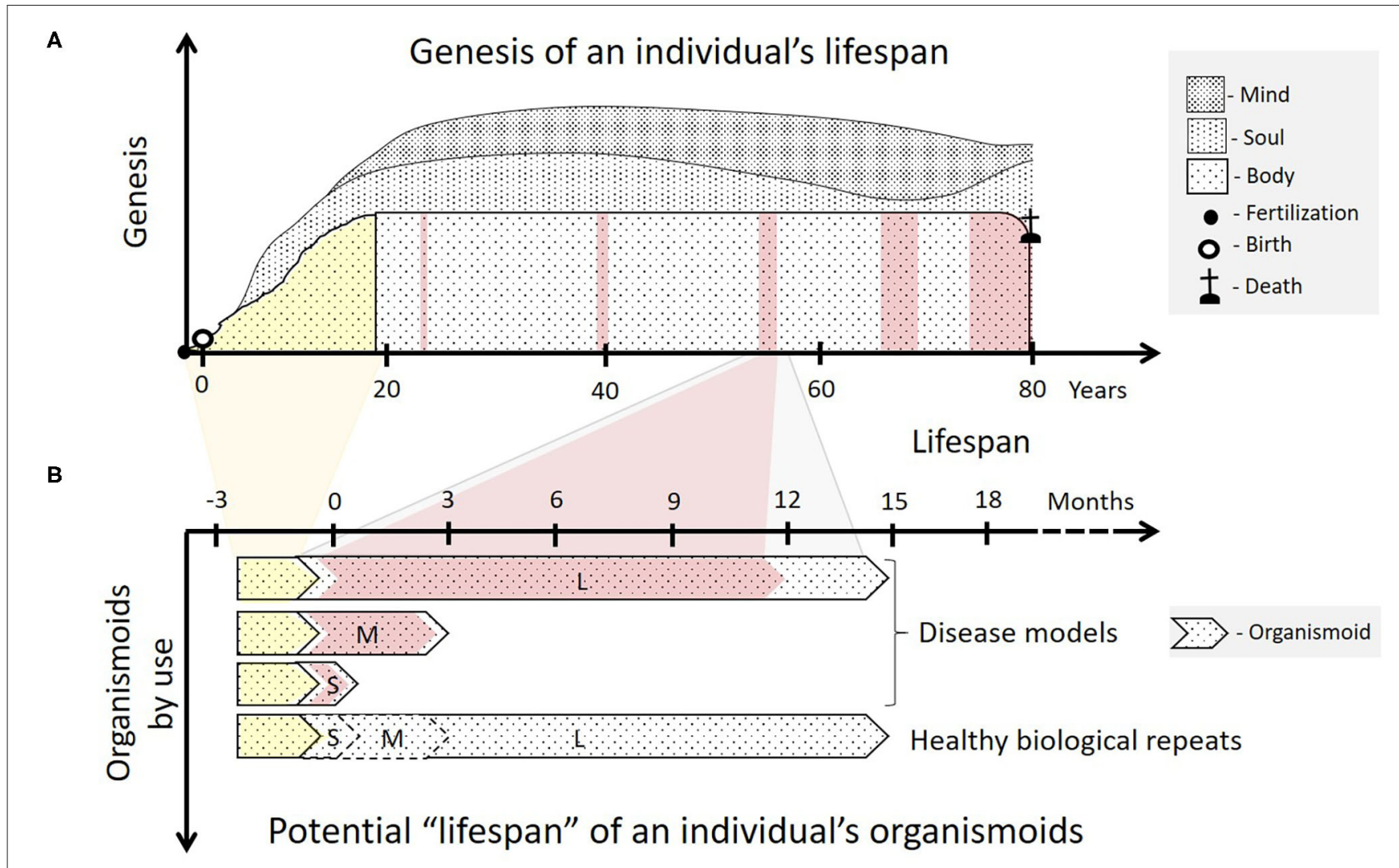

FIGURE 1 | Organismoids in the context of each human individual's fate. (A) The ontogeny (yellow) of an individual's body begins with ovum fertilization, followed by birth and ends with sexual maturity, a fully functional brain and an adult skeleton after 18 to 20 years. The adult body then goes through a lifelong period of relatively functional and architectural homeostasis lasting many decades. This adulthood is interrupted with increasing frequency by periods of ever-prolonging illness and recovery as the body ages (pink). Emotions and consciousness - the soul and the mind of a human being-begin to develop consecutively in childhood and continue to do so throughout life (sociogenesis). (B) According to the organismoid theory, personalized organismoids can be established through accelerated in vitro ontogenesis (yellow) lasting a few months. The resulting adult organismoids can then emulate a certain stage of healthy human adulthood for weeks (S-short-term), months ( $\mathrm{M}$-mid-term) or years ( $\mathrm{L}$-long-term), depending on use. These can then be utilized to emulate acute, sub-chronic and chronic disease periods (pink) and therapy-based recovery of an individual within the respective time frame. A large number of identical organismoids ensure that a sufficient number of healthy biological repeats can be run simultaneously serving as controls for full recovery of the diseased organismoids by a precision medicine or advanced therapy approach.

Moreover, such healthy organismoids are useful to evaluate preventive medicine approaches, such as vaccination for the respective individual.

advancements in the field of stem cell research and threedimensional (3D) culture systems have led to the generation of a promising complex and completely human model system called organoids. These organoids are generated from either pluripotent stem cells (PSCs) (either induced PSCs [iPSCs] or embryonic stem cells), adult stem cells (ASCs) or adult tumor tissue by self-organization. Their use for drug discovery and personalized medicine has been reviewed (11) and first proof of concept to generate personalized data has been provided (12).

Organoid tissues maintain their capacity to keep proliferating and differentiating into the different cell types of the respective organ, while preserving a stem cell pool, by carefully tuning microenvironmental cues, such as mimicking the in vivo stem cell niche. In comparison to two-dimensional monolayer cultures, 3D organoid cultures mimic more closely the physiological behavior of organs shown by gene and protein expression and metabolization capacity. The majority of organoids require an extracellular matrix environment, which is based on laminins and collagen, comparable to the physical scaffold surrounding cells in vivo. This matrix is, in most cases, animal-based and not well-defined, therefore, batch-to-batch variabilities might occur (13). Furthermore, the differentiation process of organoids, ASCor PSC-derived, depends on many different elements, such as growth factors, the matrix, matrix stiffness, cell-cell contact, cell density, oxygen level, nutrient supply or the stochastic nature of in vitro self-organization and cell fate decision. Thus, there is a high heterogeneity in the maturation and function of organoids under standard in vitro culture conditions.

Organoids derived from PSCs mimic embryonic development in vitro. Therewith, these organoids are of great value for developmental studies. Different growth factors are used to push the PSCs into the appropriate germ layer-mesoderm, endoderm, or ectoderm. Subsequently, further growth factor cocktails are used to drive the cells to form a differentiated organoid. Here, matrix proteins play a crucial role in organoid formation and are frequently used to mimic the basal lamina. 


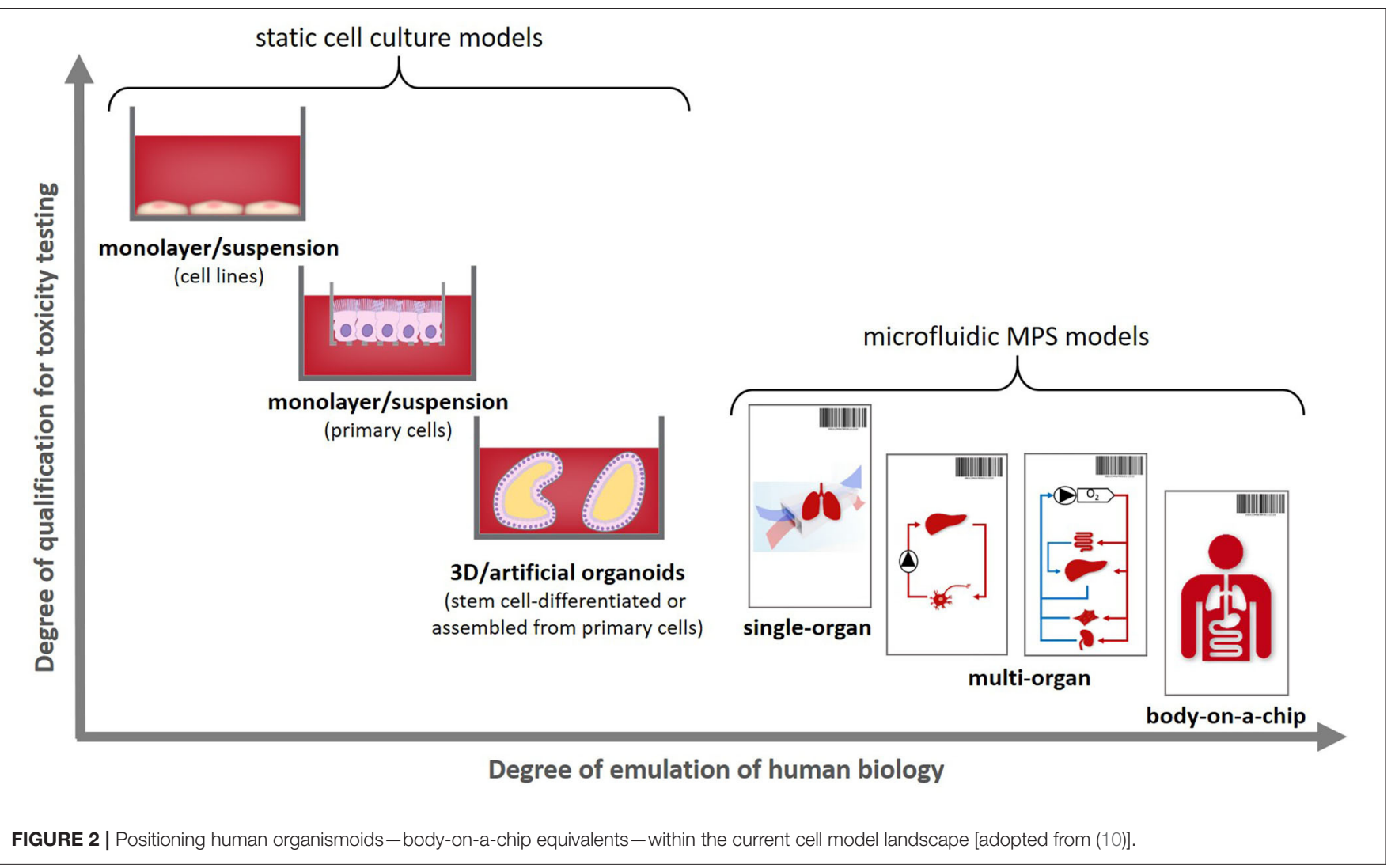

The differentiated organoids may consist of different cells typesepithelial and mesenchymal-and may even acquire initial endothelial networks by the intrinsic differentiation (14) or extrinsic addition of endothelial cells or mesodermal progenitors $(15,16)$. The period of generating PSC-derived organoids varies depending on the tissue type and usually requires between 2 weeks and 3 months (17) but can continue for half a year or longer, as seen in skin (18) or brain organoids (19).

Patient-specific PSC-derived organoids are generated by reprogramming somatic cells into iPSCs. However, this may take several months. The efficiency of organoid differentiation varies greatly between tissue types and even differentiation protocols. Furthermore, there is a limited possibility for the passaging of iPSC-derived organoids.

Organoids are difficult to generate from ASCs for some tissues, such as the brain, due to a lack of availability of tissue samples. Therefore, PSC-derived organoids are beneficial for brain organoid generation. These organoids have been cultured for up to and beyond 2 years in 3D spheroid suspension culture without passaging $(19,20)$.

Organoids derived from ASCs are generated from adult tissue having regenerative ability. Early human tooth or hair follicle development models, for example, apply mesenchymal condensation principles in vitro to generate the placode or the dermal papilla organoids, respectively from donor-derived progenitor cells $(21,22)$. However, only the epithelial portion of tissues can be made into organoids. Stromal cells, endothelial cells and nerves are missing in these models. The major benefits of ASC-derived organoids lie in the fact that they may be generated from healthy or tumor tissue. Organoid formation of ASCs normally takes only several days and the organoids are stable for long-term cultivation and expansion. Distinct growth factor cocktails are used for organoid expansion and differentiation, therefore, they can be expanded indefinitely. Biobanks of healthy and tumor organoids from patients can be generated from different organs to test drugs in high throughput screenings for further decision-making for patient treatment (17).

A large variety of human organoids has been generated using these $3 \mathrm{D}$ cultivation methods in academic labs over the past decade. Their applications and their potentials have been extensively reviewed $(13,17,23-25)$. Table 1 highlights the human organs for which organoids have been generated in static in vitro culture. However, conventional static culture systems cannot terminally differentiate the organoids into mature and fully functional organ models. Local morphogen gradients are appearing in organoids as they are forming but stable blood perfusion-driven morphogen gradients of growth factors, oxygen and other functional biochemical or biophysical cues are missing. Thus, static culture conditions limit the cultivation time due to restrictions in the supply of nutrients and waste removal from ever-growing organoids, therewith limiting their maturation grade. In the following, we will discuss how to improve organoid maturity by introducing defined spatiotemporal cues. 
TABLE 1 | Overview of human organoids generated in static in vitro culture.

\begin{tabular}{|c|c|c|c|c|}
\hline Organ & Tissue source & Culture condition & Functionality or application & References \\
\hline $\begin{array}{l}\text { Blood } \\
\text { vessel }\end{array}$ & $\begin{array}{l}\text { iPSCs, } \\
\text { epithelial stem cells } \\
\text { (ESCs) }\end{array}$ & $\begin{array}{l}\text { Spheroids in ultralow } \\
\text { attachment plates or } \\
\text { matrix-embedded }\end{array}$ & $\begin{array}{l}\text { Endothelial cells and pericytes that self-assemble into capillary } \\
\text { networks }\end{array}$ & $(26)$ \\
\hline Brain & $\begin{array}{l}\text { iPSCs, } \\
\text { ESCs }\end{array}$ & $\begin{array}{l}\text { Suspension spheroids or } \\
\text { matrix-embedded }\end{array}$ & $\begin{array}{l}\text { Unpatterned organoids contain cell clusters with forebrain, } \\
\text { midbrain, hindbrain and retinal identities that contain } \\
\text { glutamatergic, GABAergic and dopaminergic neurons as well } \\
\text { as astroglia. Patterned organoids can be differentiated toward } \\
\text { forebrain, midbrain, brainstem, cerebellum, thalamus, } \\
\text { hypothalamus, spinal cord and hippocampus identity }\end{array}$ & $(19,27-42)$ \\
\hline Liver & ASCs, ESCs, iPSCs & $\begin{array}{l}\text { Suspension spheroids or } \\
\text { matrix-embedded }\end{array}$ & $\begin{array}{l}\text { Appropriate secretion ability (albumin and urea) and drug } \\
\text { metabolic ability (CYP3A4 activity and inducibility) }\end{array}$ & $(43-56)$ \\
\hline Thyroid & $\begin{array}{l}\text { Adult thyroid-derived } \\
\text { cells }\end{array}$ & Matrix-embedded & Secretion of thyroid hormones & $(57)$ \\
\hline Pancreas & ASCs, ESCs, iPSCs & Matrix-embedded & $\begin{array}{l}\text { Secretion of insulin in response to } \\
\text { glucose }\end{array}$ & $(58-60)$ \\
\hline Optic cup & iPSCs, ESCs & Matrix-embedded & $\begin{array}{l}\text { Primitive cornea and lens-like cells, developing } \\
\text { photoreceptors, retinal pigment epithelia, axon-like projections } \\
\text { and electrically active neuronal networks }\end{array}$ & $(61-66)$ \\
\hline Intestine & ASCs, ESCs, iPSCs & Matrix-embedded & $\begin{array}{l}\text { Villus- and crypt-like structures and enterocytes, goblet, } \\
\text { enteroendocrine, and Paneth cells }\end{array}$ & $(67-71)$ \\
\hline Gastric & $\begin{array}{l}\text { ASCS, } \\
\text { iPSCS }\end{array}$ & Matrix-embedded & Used to study H pylori infection and other gastric pathologies & $(72-75)$ \\
\hline Kidney & $\begin{array}{l}\text { ASCs, } \\
\text { ESCs, iPSCs }\end{array}$ & $\begin{array}{l}\text { Spheroids or } \\
\text { matrix-embedded }\end{array}$ & $\begin{array}{l}\text { Rudimentary nephrons, and 3D culture combined } \\
\text { with active fluid flow }\end{array}$ & $(76-81)$ \\
\hline Lung & $\begin{array}{l}\text { ESCs, } \\
\text { iPSCs, fetal lung tissue, } \\
\text { ASCs }\end{array}$ & Matrix-embedded & $\begin{array}{l}\text { Rudimentary bronchiole-like structures and express alveolar cell } \\
\text { markers }\end{array}$ & $(82-87)$ \\
\hline Skin & iPSCs & $\begin{array}{l}\text { Aggregates in suspension } \\
\text { with matrix coating, skin } \\
\text { Transwell model }\end{array}$ & $\begin{array}{l}\text { Complex skin analogs with human iPSC (hiPSC)-derived } \\
\text { keratinocytes, endothelial cells and fibroblasts }\end{array}$ & $(18,88,89)$ \\
\hline Cardio & $\begin{array}{l}\text { iPSCs, } \\
\text { ESCs }\end{array}$ & Spheroids or monolayer & Contractile spheroids & $(90-94)$ \\
\hline Mammary gland & $\begin{array}{l}\text { adult mammary gland } \\
\text { tissue }\end{array}$ & In adherent or floating matrix & Could be induced to produce milk protein & $(95,96)$ \\
\hline Prostate & ASCs & Matrix-embedded & With basal and luminal cells & $(97-99)$ \\
\hline
\end{tabular}

\section{MICROFLUIDIC CELL CULTURE SYSTEMS - THE KEY TOWARD THE INTEGRATION OF PREMATURE ORGANOIDS INTO ORGANISMOIDS}

Organoids have proven to be powerful tools in emulating distinct sets of organ-specific characteristics. However, marker expression and functionality often halts at a premature stage, as described above. We have known since 1912 that the environment of in vitro cultures defines their viability and functionality (100). The isotropic microenvironmental cues that have driven organoid self-assembly and differentiation engulf organoids under traditional culture conditions rather homogenously or cover extensive surface areas hindering the spatial orientation and maturation driven by functionality. But these spatiotemporal cues originating from interacting tissues and leading to a rearrangement of cells are key to the development of mature organ functionality. Endothelial-tissue cross talk in particular and its implications for local signaling during organogenesis have been studied extensively (101-103). Vascularization of the developing central nervous system, for example, is a crucial step in brain development ensuring oxygen and nutrient supply of the rapidly dividing neural progenitors. Neural structures of the peripheral nervous system have been demonstrated to develop in noticeable alignment with blood vessels. Furthermore, the importance of endothelial cells for the maintenance of the germinal zones of the central nervous system where cerebellar cells are produced has been shown (104).

Moreover, the recombinant proteins and small molecules administered in static cultures to control lineage specification mostly promote the development of a specific subsection of cells within the organ (the parenchymal cells). Other crucial lineages, such as vascular, neuronal or immune lineages, are mostly absent, therewith silencing paracrine signaling that might become relevant during further maturation.

Allowing a finely orchestrated systemic interaction of premature organoids with other organ systems at physiologically relevant scales promotes an alignment of functionality and a higher spatial resolution of stimulation. Nature's organ building 
blocks-the smallest functional units described above-form, in their multiplicity, an entire human organ. The number of those repetitive subunits depends on the requirements signaled by the interacting organs. Therewith, organ sizes, medium flow rates and fluid residence times in organs and overall liquid to cell ratios self-adjust in a dynamic interplay of tissues.

Several approaches enabling the systemic interaction of tissue models have been devised to date-the most prominent being patient-derived xenograft (PDX) models and MPS. In the former, immunodeficient or humanized mice serve as hosts, enabling the engraftment of primarily tumor models. The interplay of grafts with local and systemic environments, also through a vascularization of the models, eventually allows for a nutrition of cells and a propagation of models. However, species' differences between the host organism and the patient's tissue prevents a complete match of biology. A plethora of drawbacks have been described in using these methods, but the assets of having a systemic circulation supporting the models could be shown.

Substantial efforts have been made over the past two decades to improve organ model culture conditions by introducing them into MPS. Dozens of human organ equivalents in MPS have been established using primary- and cell linebased models and have been reviewed in great detail (105111). It is well-documented that the maturation of organ function can be achieved by closely emulating organotypic microenvironments regarding biochemical, physical, or electrical stimuli (106).

Once the notion became clear that the autologous nature of such systems is essential, the MPS community started to establish stem cell-derived models on-chip. Table 2 summarizes the very recent achievements in this area. Furthermore, it is only a matter of time before the missing organoids for the creation of minimal organismoids are established.

A huge variety of additional human tissue and organ models have been published. However, attempts at organismal onchip homeostasis have so far failed to integrate the systemic components, such as whole blood supply through vascularized microvessels, a personalized (autologous) immune system and tissue innervation. Here, we have extended the theorization of creating MPS-based organismoids by integrating the premature organoids of each relevant organ system into a self-regulating vascularized and innervated systemic circulation.

We hypothesized already in 2012 that "the lack of a dynamic interplay between organ-specific cell types, with their vascular and stromal tissue bed, and the absence of adult stem cell and progenitor niches for local regeneration, are responsible for the crucial missing capabilities of current 'human-on-a-chip' systems" (5). The vascularization of whole microfluidic circuits on-chip was shown as early as 2013 (132), followed by fascinating work on the generation of vascularized organ models on-chip (133-136). As of today, high-throughput platforms generating vascularized single-tissue models on-chip are commercially available (137). The combination of both technologies generating a closed vascularized circuit containing multiple organs onchip is within reach, allowing for the next level of physiological complexity - the perfusion of whole blood or a defined substitute containing all relevant components.
The organismoid theory hypothesizes that the generation and renewal of all crucial whole blood components-red blood cells, platelets, white blood cells and plasma components-is feasible and will lead to a self-sustained systemic organismoid. Therefore, a steady functional on-chip hematopoiesis is required. Several approaches to model the human bone marrow-based hematopoietic stem cell niche using MPS have been described $(8,138,139)$. Adapting the model of Sieber et al. (138) to include cytokines important for cell differentiation and stem cell maintenance has enabled the continuous, robust generation and maintenance of cells from erythroid, myeloid and megakaryocyte lineages, while simultaneously maintaining stem and progenitor cell populations for at least 24 days (Figure 3). In brief, bone marrow chips were established as described by Sieber et al. (138) but with the modification of media to include additional cytokines, as outlined in Chou et al. (139). Cells were sampled from the recirculating media and deposited directly onto slides using a cytospin centrifuge, before staining with Wright's stain and imaging. The donor information for the cells used in the study is detailed in Table 3.

The academic MPS development landscape has provided a number of other indicators that particular elements of blood perfusion can be recapitulated using MPS. The capability of emulating platelet-induced blood coagulation has been demonstrated by Westein et al. (140) and numerous publications describe the circulation of immune cells in MPS and their settlement in organ models on chips (141-143).

As soon as it comes to organismoid-based physiological whole blood provision to all on-chip organ equivalents, the assets of using stem cell-derived organoids of an autologous source becomes relevant to prevent foreign organ model rejection by the immune system. Multi-organ systems published previously were mostly composed of tissues from different donors, which made the rejection-free integration of an individual's immune system, as the major defense mechanisms of any human organism, impossible. The first steps toward an autologous co-culture of several cell types from one iPSC donor were reported as early as 2013 (144). The premature nature of iPSC-derived organoids raised the question of how such organoids can be finally differentiated to match the functionality of their respective human counterparts. Here, the organismoid theory proposes the principle of terminal on-chip differentiation, guided by integrated organismal cross talk and artificially accelerated "training programs" for key organs and systems, such as xenobiotic panel exposure for the liver, multi-antigen vaccination for the immune system or artificial exposure to steroid hormones for the accelerated maturation of the sexual organs. The first hint that further on-chip maturation is triggered by organ-organ interaction in a physiology-based 4-organ chip was demonstrated in 2019 (131), where the expression of albumin and MRP2 genes increased significantly over a period of 14 days in an iPSCderived premature liver model, driven solely by differentiation factor-free co-culture with iPSC-derived intestinal, kidney and neuronal models (Figure 4).

Such data support the organismoid theory's concept that once liver functionality matches the requirements of the systemic organismoid, a regular application of nutrients through the 
TABLE 2 | Examples of the MPS-based models established recapitulating functions of the key human organs.

\begin{tabular}{|c|c|c|c|c|c|c|}
\hline Organ & $\begin{array}{l}\text { Substructure/Cell } \\
\text { types }\end{array}$ & Tissue source & $\begin{array}{l}\text { (Patho-) } \\
\text { Physiology }\end{array}$ & Chip type & MPS advantage & References \\
\hline \multirow[t]{5}{*}{ Brain } & $\begin{array}{l}\text { Unpatterned } \\
\text { (forebrain }+ \\
\text { hindbrain) }\end{array}$ & hiPSCs & $\begin{array}{l}\text { Healthy, + prenatal } \\
\text { nicotine exposure }\end{array}$ & $\begin{array}{l}\text { Continuous } \\
\text { unidirectional perfusion }\end{array}$ & $\begin{array}{l}\text { Enhanced expression of cortical layer markers } \\
\text { (TBR1 and CTIP2) under perfusion }\end{array}$ & $(112,113)$ \\
\hline & $\begin{array}{l}\text { Unpatterned } \\
\text { (forebrain + } \\
\text { midbrain + } \\
\text { hindbrain) }\end{array}$ & hESCs & Healthy & $\begin{array}{l}\text { Continuous } \\
\text { unidirectional perfusion }\end{array}$ & $\begin{array}{l}\text { Creation of signaling gradients that mimic } \\
\text { developmental patterning for neural tube } \\
\text { formation }\end{array}$ & $(114)$ \\
\hline & $\begin{array}{l}\text { Blood-brain barrier } \\
\text { (BBB; endothelial } \\
\text { cells + motor } \\
\text { neurons) }\end{array}$ & iPSCs & Healthy & $\begin{array}{l}\text { Continuous } \\
\text { unidirectional perfusion }\end{array}$ & $\begin{array}{l}\text { Increased calcium transient function and } \\
\text { chip-specific gene expression under perfusion }\end{array}$ & $(115)$ \\
\hline & $\begin{array}{l}\text { BBB (endothelial } \\
\text { cells }+ \text { neural } \\
\text { progenitor) }\end{array}$ & iPSCs & $\begin{array}{l}\text { Healthy }+ \\
\text { diseased } \\
\text { (Huntington's } \\
\text { disease) }\end{array}$ & $\begin{array}{l}\text { Continuous } \\
\text { unidirectional perfusion }\end{array}$ & $\begin{array}{l}\text { Physiologically relevant TEER and BBB } \\
\text { permeability, capillary wall protected neural } \\
\text { cells from plasma-induced toxicity }\end{array}$ & $(116)$ \\
\hline & $\begin{array}{l}\text { GABAergic } \\
\text { neurons and } \\
\text { astrocytes }\end{array}$ & iPSCs & Healthy & $\begin{array}{l}\text { Continuous } \\
\text { bidirectional perfusion }\end{array}$ & & $(117)$ \\
\hline Optic Cup & Retina & hiPSCs & Healthy & $\begin{array}{l}\text { Continuous } \\
\text { unidirectional perfusion }\end{array}$ & $\begin{array}{l}\text { Recapitulation of the interaction of mature } \\
\text { photoreceptors with retinal pigment epithelium }\end{array}$ & $(118)$ \\
\hline \multirow[t]{2}{*}{ Liver } & $\begin{array}{l}\text { Hepato- and } \\
\text { cholangiocytes }\end{array}$ & hiPSCs & Healthy & $\begin{array}{l}\text { Continuous } \\
\text { unidirectional perfusion }\end{array}$ & $\begin{array}{l}\text { Improved cell viability, higher expression of } \\
\text { endodermal mature hepatic genes and } \\
\text { improved functionality under perfusion }\end{array}$ & (119) \\
\hline & Hepatocytes & hiPSCs & Healthy & $\begin{array}{l}\text { Continuous } \\
\text { unidirectional perfusion }\end{array}$ & $\begin{array}{l}\text { Higher potential hepatic progenitor cells to } \\
\text { hepatic organoids under perfusion }\end{array}$ & $(120)$ \\
\hline Pancreas & $\begin{array}{l}\text { Islet-specific } \alpha \text { - } \\
\text { and } \beta \text {-like cells }\end{array}$ & hiPSCs & Healthy & $\begin{array}{l}\text { Continuous } \\
\text { unidirectional perfusion }\end{array}$ & $\begin{array}{l}\text { Enhanced expression of pancreatic } \beta \text {-cell gene } \\
\text { and protein expression and increased } \beta \text {-cell } \\
\text { hormone production under perfusion }\end{array}$ & $(121)$ \\
\hline \multirow[t]{2}{*}{ Heart } & Cardio-myocytes & hiPSCs & $\begin{array}{l}\text { Healthy }+ \\
\text { diseased (Barth } \\
\text { syndrome) }\end{array}$ & $\begin{array}{l}\text { Continuous } \\
\text { unidirectional perfusion }\end{array}$ & $\begin{array}{l}\text { Enabled description of metabolic, } \\
\text { structural and functional abnormalities } \\
\text { associated with Barth syndrome }\end{array}$ & $(122)$ \\
\hline & $\begin{array}{l}\text { Cardio-myocytes } \\
+ \text { endothelial cells }\end{array}$ & hiPSCs & Healthy & $\begin{array}{l}\text { Continuous } \\
\text { unidirectional perfusion }\end{array}$ & $\begin{array}{l}\text { Endothelial cells align with the flow and form } \\
\text { tube-like networks in the cardiac muscle } \\
\text { channel }\end{array}$ & $(123)$ \\
\hline \multirow[t]{4}{*}{ Intestine } & Duodenum & $\begin{array}{l}\text { Human ASCs } \\
\text { (tissue biopsies) }\end{array}$ & Healthy & $\begin{array}{l}\text { Continuous } \\
\text { unidirectional perfusion }\end{array}$ & $\begin{array}{l}\text { Human-relevant functionality is superior to that } \\
\text { of organoids alone }\end{array}$ & $(124)$ \\
\hline & Unpatterned & hiPSCs & Healthy & $\begin{array}{l}\text { Continuous } \\
\text { unidirectional perfusion }\end{array}$ & $\begin{array}{l}\text { Polarized, contains all the intestinal epithelial } \\
\text { subtypes and is biologically responsive to } \\
\text { exogenous stimuli }\end{array}$ & $(125)$ \\
\hline & Small intestine & $\begin{array}{l}\text { Human ASCs } \\
\text { (tissue biopsies) }\end{array}$ & Healthy & $\begin{array}{l}\text { Repeated unidirectional } \\
\text { perfusion }\end{array}$ & $\begin{array}{l}\text { Removal of dead cells from the organoid tubes } \\
\text { under perfusion allowed long-term culture }>1 \\
\text { month }\end{array}$ & $(126)$ \\
\hline & Unpatterned & hiPSCs & Healthy & $\begin{array}{l}\text { Continuous } \\
\text { unidirectional perfusion }\end{array}$ & Luminal waste removal through continuous flow & $(127)$ \\
\hline Stomach & Gastric organoids & hiPSCs & Healthy & $\begin{array}{l}\text { Continuous closed loop } \\
\text { perfusion }\end{array}$ & $\begin{array}{l}\text { Rhythmical stretch and } \\
\text { contraction-reminiscent of gastric motility }\end{array}$ & $(128)$ \\
\hline \multirow[t]{2}{*}{ Kidney } & $\begin{array}{l}\text { Glomerolus } \\
\text { (podocytes) }\end{array}$ & hiPSCs & Healthy & $\begin{array}{l}\text { Continuous } \\
\text { unidirectional perfusion }\end{array}$ & $\begin{array}{l}\text { Differential clearance of albumin and inulin } \\
\text { when co-cultured with human glomerular } \\
\text { endothelial cells }\end{array}$ & (129) \\
\hline & $\begin{array}{l}\text { Glomerolus }+ \\
\text { tubulus organoid }\end{array}$ & hiPSCs & Healthy & $\begin{array}{l}\text { Continuous } \\
\text { unidirectional perfusion }\end{array}$ & $\begin{array}{l}\text { Generation of perfusable vascular networks } \\
\text { and better cell maturation under perfusion }\end{array}$ & $(130)$ \\
\hline Multi-organ & $\begin{array}{l}\text { Brain, intestine, } \\
\text { kidney, liver }\end{array}$ & hiPSCs & Healthy & $\begin{array}{l}\text { Continuous circular } \\
\text { perfusion }\end{array}$ & $\begin{array}{l}\text { Co-culture over } 14 \text { days in one common } \\
\text { medium deprived of tissue-specific growth } \\
\text { factors }\end{array}$ & (131) \\
\hline
\end{tabular}

intestinal model and removal of waste substances through the kidney model will suffice to maintain functional homeostasis of the organismoid.
The majority of plasma proteins in humans are produced by the liver with albumin at a concentration of about $40 \mathrm{~g} / \mathrm{L}$, plasma being by far the largest component. In addition, the liver 


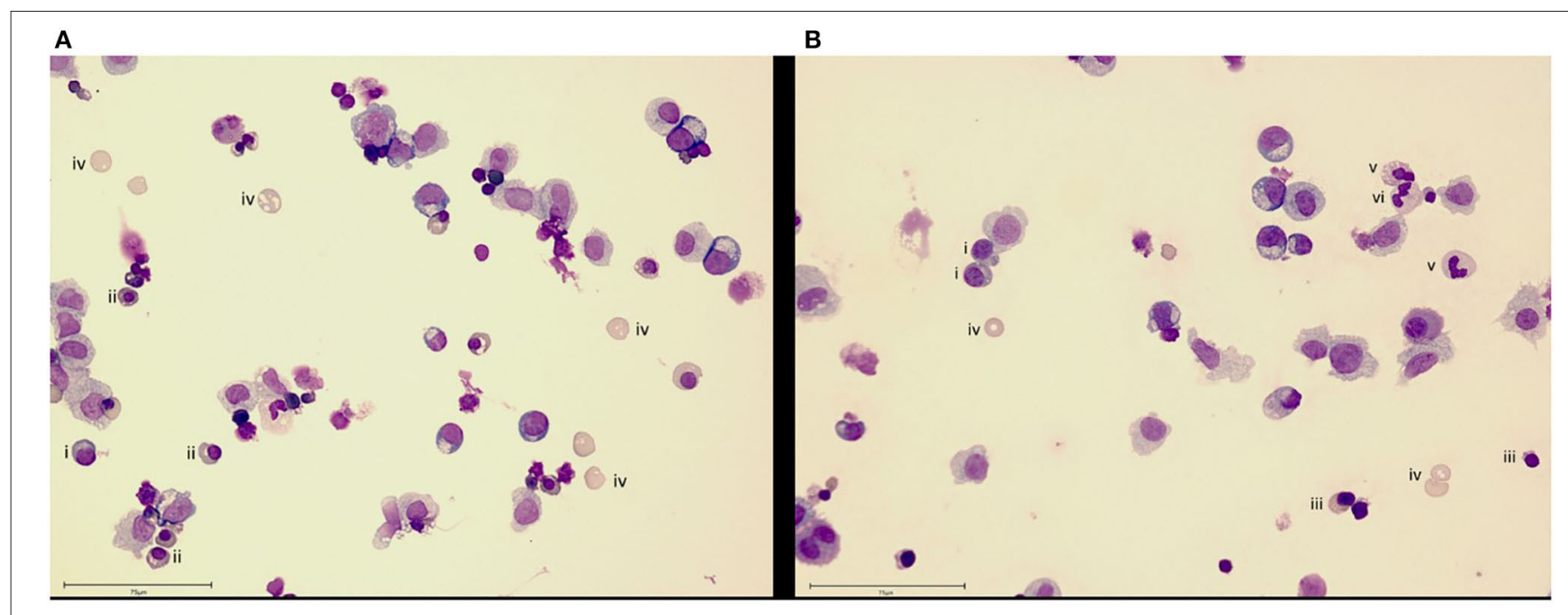

FIGURE 3 | Bone marrow cell maintenance and differentiation in an MPS. Culture of human CD34+ cells on a human mesenchymal stem cell-seeded scaffold in the recirculating HUMIMIC Chip2 for (A) 17 or (B) 24 days shows differentiation into erythroid (day 17) and then, additionally, neutrophil (day 24) lineage cells. Cells are identified as (i) basophilic normoblast, (ii) polychromatic normoblast, (iii) orthochromatic normoblast, (iv) reticulocyte, (v) band cell and (vi) neutrophil. Scale bar-75 $\mu$ m.

TABLE 3 | Stem cell donor information for the bone marrow MPS.

Human Mesenchymal Stem Cells (MSC)

Human CD34+ Hematopoietic Stem Cells (HSC)

\begin{tabular}{lllllllll}
\hline Donor (Lot \#) & Sex & Age & Race & & Donor (Lot \#) & Sex & Age & Race \\
\hline 0000451491 & Male & 25 & Caucasian & & 0000680575 & Female & 21 & Black \\
\hline
\end{tabular}

is a gatekeeper for toxicants and xenobiotics arriving through the food. Finally, it keeps homeostatic conditions regarding protein, carbohydrate and amino acid metabolism throughout the circulation. A plethora of MPS literature has provided evidence that human liver equivalents on chips composed of primary or iPSC-derived hepatocytes are capable of continuously secreting albumin and other proteins into the circulation (119). Another important protein component is the immunoglobulin $\mathrm{G}$ fraction produced by white blood plasma cells, reaching physiological levels of 7-16 g/L in the plasma protein fraction in humans. Very few MPS have aimed to generate immunoglobulins in modeling immune tissues, but an artificial lymph node has made initial progress here (145). Some other organs add crucial regulatory proteins to the plasma. Insulin secreted by the pancreatic islets and interacting with the liver to control the body's glucose-based energy balance through the regulation of glucose consumption, storage and release is such a key regulator. A stable pancreatic islet-liver co-culture MPS demonstrating the capability of an MPS to physiologically manage the secretion and organ interaction capacity for insulin was established in 2017 (146). Regarding plasma properties, it still remains a challenge to increase the plasma protein concentration generated on-chip toward physiological levels of $60-80 \mathrm{~g} / \mathrm{L}$, which is a factor of outstanding importance to leverage the physiological transport properties of albumin, deliver the hundreds of other functional proteins to their sites of action, and provide the right viscosity and flow dynamics for the transport of blood cells across the organism. The complete separation of the organ models from the blood flow by endothelial cells is a basic prerequisite for this and will provide progress in that field in the near future.

A preliminary adjustment of the plasma composition by technical means is feasible by closely monitoring metabolic activities on-chip by online sensors and might lead to an advanced maturation of organ models in the long term. Here, the use of automated systems maintaining a close observation of on-chip cultures will become an essential component (147).

Sensors can generally play a crucial role in the implementation of the organismoid theory, extending an individual's data generation beyond any currently available. On the one hand, the sensors can be inherent in the system. Analogous to pulse oximetry, for example, the oxygen saturation in the blood of an organismoid can be measured using different optical spectra of the various hemoglobin derivatives. In addition, pulse oximetry provides qualitative information about the pulsatile properties of the blood (148). The measurement of the oxygen saturation can be performed using miniaturized sensors or spatially resolved by using hyperspectral imaging techniques. The measurement of the oxygen saturation provides important information about the oxygen transport capacity, oxygen distribution and, in combination with microparticle imaging velocimetry analysis, the absolute oxygen consumption rate of each organoid incorporated into an organismoid (149).

On the other hand, the sensors can be embedded directly into the MPS. In parallel with the body area network 

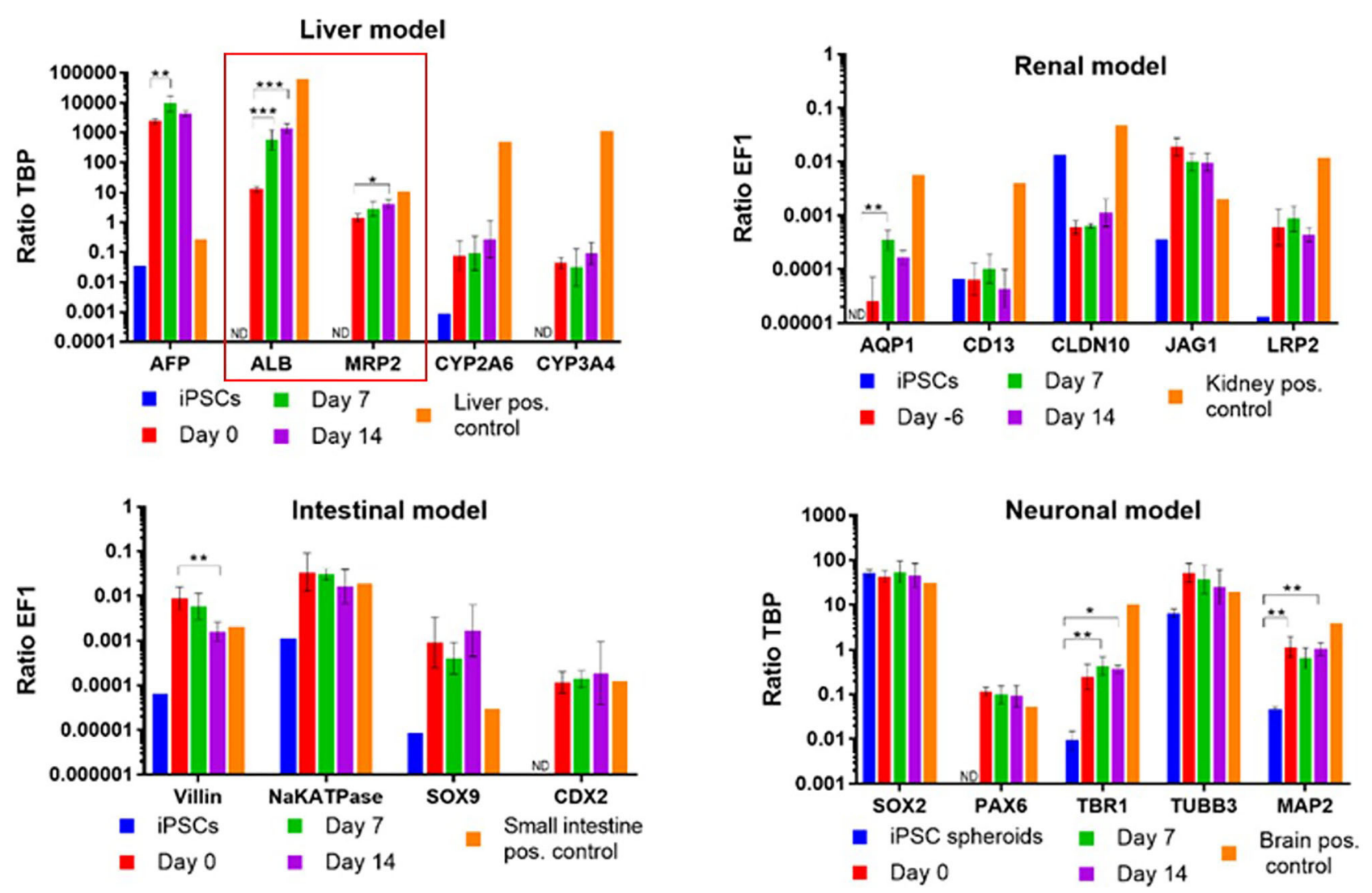

FIGURE 4 | Albumin and MDR2 gene expression increased steadily from day 0 to 14 in a 4-organ chip composed of iPSC-derived premature intestinal, liver, kidney, and neuronal organ models integrated in a physiology-based common media circulation. Feeding of differentiation factor-free medium solely through the intestinal model was performed. One-way ANOVA with Tukey's multiple comparisons test was used for statistical analysis $\left({ }^{\star} p<0.05,{ }^{* \star} p<0.01,{ }^{* \star *} p<0.001\right)$. Data shown as Mean + SD.

technology for the health monitoring of the human body (150), the integration of multiple sensors is fundamental to allow the continuous online monitoring of organ-specific reactions and dynamic tissue responses. Multi-sensor integrated platforms are especially important for the development of MPSbased organismoids in which the monitoring of function of various organs requires a combination of different sensing principles. Transepithelial electrical resistance measurement is among the most popular non-invasive techniques and has been successfully integrated into MPS to assess the barrier integrity and junction dynamics of endothelial or epithelial models (151). Electrical impedance spectroscopybased methods overcome conventional transepithelial electrical resistance measurement techniques by exploiting extended frequency domain data, thus, allowing an evaluation of tissue barrier function at different maturation stages (152). Impedance-based techniques can be further enhanced when coupled with multi-electrode arrays to provide localized sensing and electrical stimulation in relevant microenvironments of an organismoid. Applications include the recapitulation of cardiomyocyte or motor neuron innervation by direct electrical stimulation of the contractile activity (153), and the possibility of producing surrogate electroencephalograms from neuronal activities, which represents an added value to Parkinson or Alzheimer's disease modeling.

The innervation of organ models plays a pivotal role in their development, maturation, regulatory control, regeneration and pathology. We know from organ transplant surgeries that the ablation of autonomic neuronal connections may cause poor graft functionality and detrimental health effects (154). Similarly, the importance of innervation in the regulation of stem cells and/or their niches in most organs and tissues has been well-documented. Autonomic nerves impact tissue growth during the initial organogenesis and regeneration and, similarly, impact aging or the development and progression of disease. The introduction of innervation to in vitro models has so far been mostly neglected due to the complexity of achieving proper guidance and integration of neurons into nonneural tissue models. First steps have been taken to model both the synaptic junction between neural models and the neuroeffector junction formation between neural and non-neural tissue models both in static and MPS organoid cultures during the last decade. A major challenge in this field is the directed guidance of axon growth from the neuronal to the effector tissue. Consequently, the development of MPS that enable the assembly and cultivation of stem cell-derived myelinated motor neurons, 
as published by $(155,156)$, are an important basis for enabling functional innervation in MPS. Understanding how tissuederived neurotrophic and neural guidance factors drive axon growth and determine its directionality during development will be instrumental.

Stem cell-derived regionalized brain organoids have been shown to possess the intrinsic capability of forming synaptic innervations with each other. Multiple groups have described the fusion of regionalized stem cell-derived cortical and subpallium organoids to model the migration of GABAergic interneurons from the subpallium organoids into the glutamatergic excitatory, neuron-rich cortical organoids, where they integrate functionally into local excitatory circuits (157-159). This intrinsic capability can also be exploited for the assembly of the other regionalized brain organoids, as has been shown for stem cell-derived cortical and thalamic organoids (159).

Roger D. Kamm's group has shown that stem cell-derived motor neuron organoids can build functional neuromuscular junctions (NMJs) with 3D skeletal muscle bundles in a patterned chip platform which enhanced the guided innervation of tissue constructs. Motor neurons in this setup were transduced with the light-sensitive channel rhodopsin-2, which enabled lightactivated muscle contraction to show the formation of functional NMJs (160). Another study with stem cell-derived cerebral organoids showed that they could develop pronounced axon tracts, which functionally innervated into rodent spinal cord explants where they caused concerted muscle contractions easily distinguishable from local spontaneous contractions and could be evoked by electrical stimulation (31). The positive effects of nerve innervation on the maturity and functionally of cardiac tissue was shown by (161), where the innervation of sympathetic neurons increased the spontaneous beat rate of primary cardiac cells.

Protocols have been developed to omit the complex guidance of axon growth to the respective non-neural tissue organoid; these allowed the simultaneous differentiation of neural and non-neural tissue in one organoid. This has been achieved for neuromuscular organoids that contain functional NMJs and myelinated axons in the presence of terminal Schwann cells and contractile activity of the muscle part, which stopped upon blockage of acetylcholine receptors (162). Such interorgan spheroids were also realized for a combination of forebrain and optic vesicles, where bilateral light-sensitive optic vesicles developed on the surface of forebrain organoids and formed electrically active primitive sensory circuits (62).

The next big steps in the field of in vitro tissue innervation will be to build a closed neuronal circuit model with a sensory (e.g., optic cup organoid) and effector (e.g., muscle fiber) that are interconnected by a cortical model, and achieving the myelination of motor neurons axons by Schwann cells or oligodendrocytes $(156,163)$. Another promising approach is the combination of on-chip vascularization and innervation. In vivo peripheral nerves grow along blood vessels. We hypothesize that this route of innervation will also become relevant on-chip once the closed vascular system is established. The advantages of the interconnection of vascularization and innervation were shown by (116), who demonstrated vascular-neural interaction leading to a more in vivo-like gene expression signature and increased calcium transient in a MPS equipped with stem cell-derived brain microvascular endothelial cells and motor neurons.

In addition to the positive effects of physiological tissue innervation by (motor-)neurons, modeling of the peripheral nervous system is also of interest for the field of neurodegenerative diseases such as amyotrophic lateral sclerosis. In vitro (MPS) models have the potential to become an important cornerstone for studying the pharmacological effects of compounds on the NMJs. A first step in this direction was recently published by (164) on the Mimetas OrganoPlate platform, which hosts 40 microchips with iPSC-derived motor neurons. The latter showed pronounced axon outgrowth and could be coupled to muscle tissue to form NMJs.

Another critical aspect regarding organismal homeostasis is the interaction of autonomic innervation with the immune system. Looking at the digestive tract, for example, the gut immune system impacts on the local enteric nervous system, the extrinsic neurons of sympathetic and parasympathetic systems and, ultimately, on brain functions, such as mood, cognition and mental health. Conversely, the brain is able to modulate immune function in the intestine through the vagus nerve via the intestinal cholinergic anti-inflammatory pathway (165). Innervation in primary lymphoid organs, such as the bone marrow, and secondary lymphoid organs, such as the spleen, has been well-studied and the ability of the nervous system to influence immune homeostasis and inflammation in these niches has been shown (166).

Another important aspect to emulate systemic organismal pathways on chips includes the integration of the relevant donorspecific microbiota to mimic a patient's interaction with the respective metabolites in general (167-169).

It appears that innervation, vascularization, lymphatics, microbiota, and the emulation of a human-like enterohepatic circulation of bile products are indispensable prerequisites to bridge the gap between the simple physical combination of organoids in multi-organ MPS and real tissue interaction and homeostasis in an organismoid.

The latter needs a biological combination of the prime organ equivalents from at least 10 human systems (as highlighted in the introduction) and their biological interconnection through vasculature, innervation and lymphatics. Two early attempts to establish MPS containing at least 10 technically interconnectable organ culture compartments have already been published. Those prime examples include the 13-organ culture compartment system of the Shuler Lab at Cornell University (170) and the 10-organ culture compartment PhysioMimix ${ }^{\mathrm{TM}}$ system of the Griffith lab at MIT (171). Both systems have been successfully operated with biological materials in the culture compartments for seven or more days. However, both lack a biological blood vessel interconnection, lymphatics and organ innervation.

\section{WHAT ORGANISMOIDS MIGHT DELIVER TO OUR HEALTHCARE SYSTEM}

According to the organismoid theory, organismoids are biological replica of the living human body in vitro, reduced in scale as far as possible. They are created by the systemic 
physiological integration of the functional units of the major human organs into an organismal, self-sustained template that reflects the systemic organization of the human body. The on-chip fast-track differentiation of stem cell derived organ equivalents originates from their cross talk and a physiological reliance on each other. The extreme reduction in scale is due to the goal of generating a large number of replicates of the organismoid of an individual. Large numbers of such identical, minute, mindless and emotion-free physiological in vitro equivalents of an individual's mature human body can be maintained at self-sustained functional healthy homeostasis over very lengthy time frames. They are open to perturbation leading to the natural or artificial induction of diseases. The diseased organismoids are hypothesized to emulate the pathophysiology of the respective patient's disease precisely. This, in turn, may enable the performance of predictive patient-specific organismoid studies to determine the most effective personalized therapy for the patient concerned. Similar to clinical studies on patient cohorts, statistically verified predictions can then be generated with the advantage that genetically identical replicates of the patient's organismoids can be compared under physiological and pathophysiological conditions. Two major usage scenarios can be derived from that. One is related to a cutting-edge improvement of an individual patient's personal treatment in the real world; the other has the potential to change the drug development paradigm on a clinical trial level, saving enormous amounts of time and capital expenditure.

Regarding the first scenario, organismoids can be used in predictively selecting, scheduling and dosing an individual patient's personalized therapy or medicine accurately along their disease progression. This can significantly decrease the potential risk to each and every patient by the early detection of unsuccessful treatment schedules. Figure 5 summarizes the advantages of applying organismoids for personalized precision medicine in more detail. The figure illustrates the concept and principles of the organismoid approach to select the best fitting precision medicine applied to your personalized illness. As a hypothetical example, cancer is chosen to be the illness.

Your lifespan might eventually include periods of lifethreatening illness, for example, cancer growth (top: Bluebordered arrow). A pluripotent stem cell bank is established from your healthy cells. Subsequently, a large number of identical healthy organismoids are generated within a few months (yellow triangle). Various options are currently available to treat cancer, therefore, relevant test groups are created, including placebo treatments, other treatment groups and healthy recovery controls (in the black-bordered arrow). In this hypothetical example, within a few weeks, the CAR-T cell therapy in combination with a checkpoint inhibitor turns out to be the fastest and most effective cure for you. Therefore, this therapy is immediately and successfully applied.

According to the organismoid theory, an individual's stem cell bank can be created when healthy or from a healthy organ when illness occurs. Preventive stem cell banking (e.g., from umbilical cord blood) is already in use and will be the choice in the future as it takes time. The near-to-human element of the theory provides precise test results which animal tests in patientderived xenograft models or human patient-derived organoids cannot achieve. Xenograft models are phylogenetically distant and, therefore, cannot provide sufficient tumor outgrowth. Additionally, they do not have a patient's immune background to fight cancer. Patient-derived organoids are also not embedded in the patient's immune system and lack systemic interaction with the organism.

Regarding the second scenario, the average success rate of drug candidates entering clinical trials to become an approved drug has been below $20 \%$ for decades; no other industry can afford this inefficiency of translating any prototype into a marketed product. Poor predictivity of the preclinical safety and efficacy evaluation program of candidate drugs using laboratory animals is the prime reason for that inefficiency. Lengthy clinical trials averaging 13.5 years and bearing cumulative costs reaching as much as 2.5 billion USD to get a new medicine approved are the consequences (106). Simultaneously, a revolution in therapeutic strategies has emerged over the last three decades based on biologics - using the human body's own tools to fight diseases. The expanding biological complexity of medicines, from synthetic low molecular weight drugs toward, for example, human monoclonal antibody proteins and, finally, patientspecific autologous cell therapies, has dramatically increased the chances of cure for patients in recent years. However, this trend has, just as dramatically, reduced the chances of being able to predict the safety and efficacy of such therapies by applying preclinical laboratory animal testing due to the increasingly human origin of such advanced therapeutic medicinal products (172). In addition, the pricing along this rising biological gradient of medicines has become the major roadblock for the socially equitable availability of such therapies for all patients in the last few years. At the beginning of that trend, the average daily dose of a biologic drug cost 22 times more than that of a small molecule and accounted for a few dozen USD (173). However, best in class protein biologics-monoclonal antibodies-reached an annual average price for a patient's therapy course of about 96,000 USD in 2017 (174), which corresponds to roughly 263 USD per day. Nowadays, the price for the most disruptive innovation in advanced cell therapies-highly effective autologous CAR-T cell therapiesin Germany, for example, rose to as much as $320,000 €$ for a patient's treatment, considering a payment "at" result (175). This therapy is a single day infusion. An ever growing misbalance between the efficacy of wonder-performing drugs and the patient's financial ability to access them has become a serious social and economic conflict for our healthcare systems on a global scale.

Organismoids have the potential to break this cost spiral by bringing about a paradigm shift in drug development. The stakeholder report of the MPS community produced in 2016 already projected a decrease of the cumulative drug development costs by a factor of five and a halving of the drug development times once MPS-based clinical trial-like studies on organismoids have enabled the accurate prediction of efficacy, safety, dosing and scheduling for any new medicine or therapy prior to use in human and replacing animal testing and Phase 


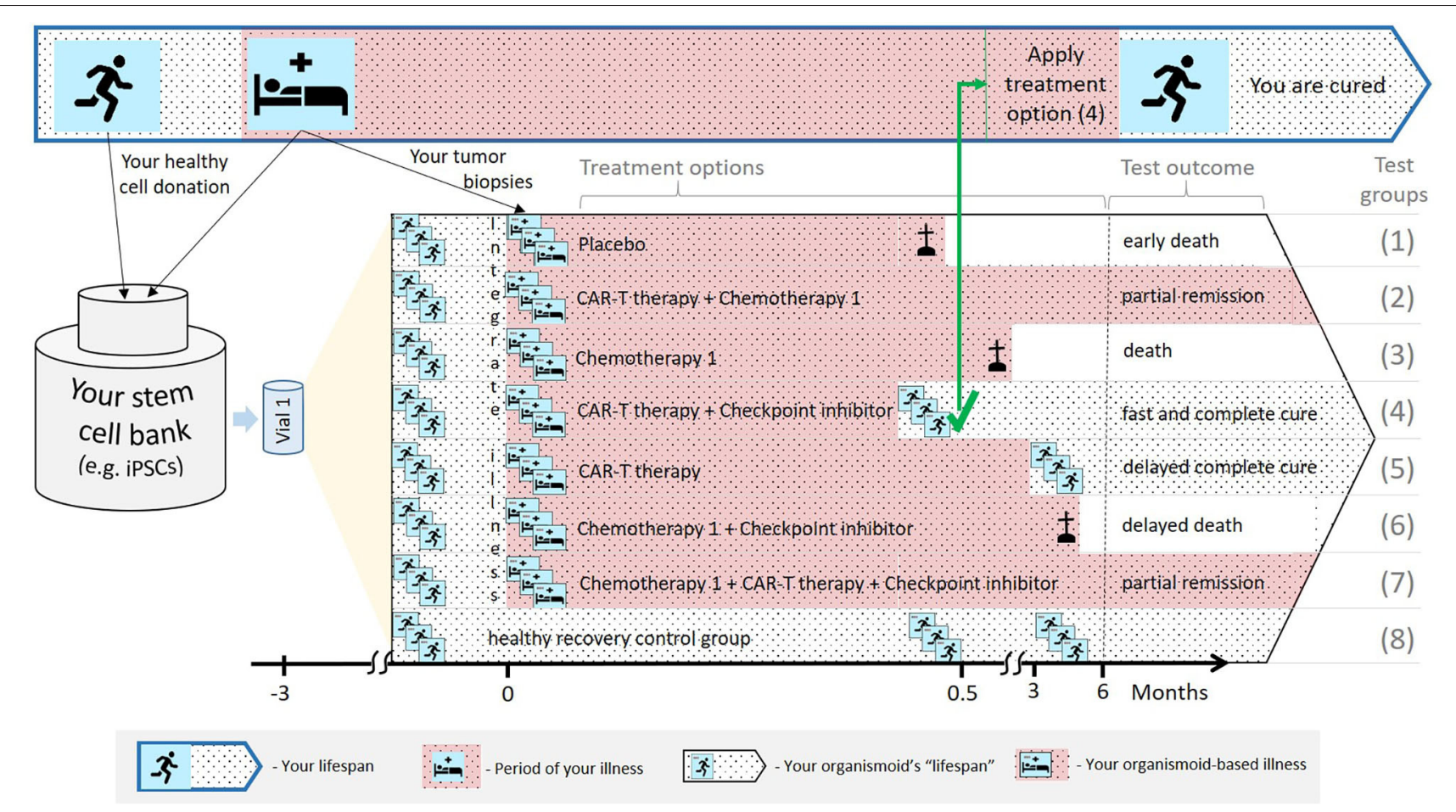

FIGURE 5 | A hypothetical example illustrating how the organismoid theory can be utilized in personalized medicine.

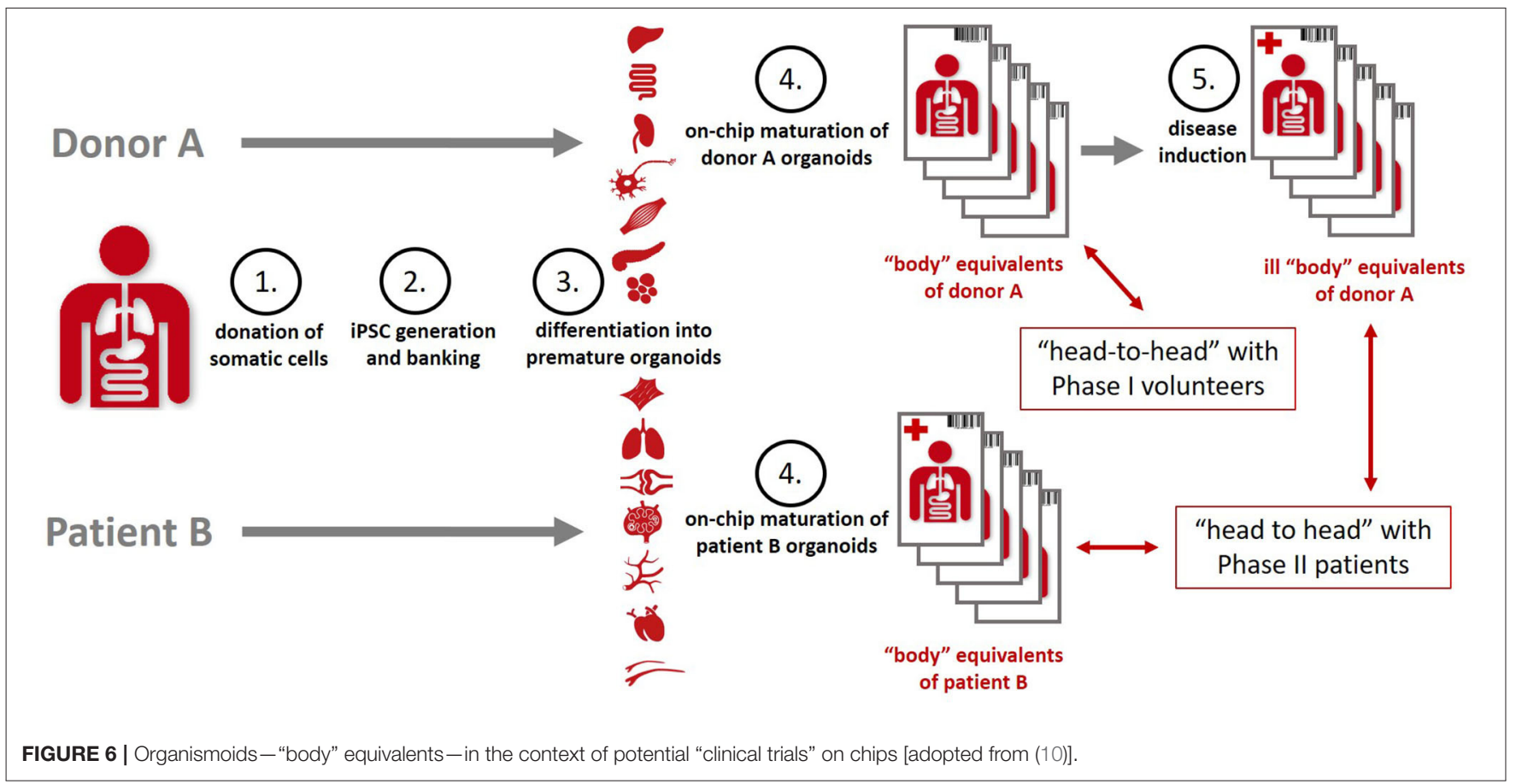

1 and 2 clinical trials (106). An advanced roadmap toward the qualification of the precision of prediction of "clinical trials" (Figure 6) running minute personalized "body" equivalents (organismoids) in on-chip studies head-to-head with clinical trials was sketched in 2018 by the Investigative Toxicology Leaders Forum (10).

In order to achieve that, a set of healthy and diseased organismoids representing the patient's disease status and their 


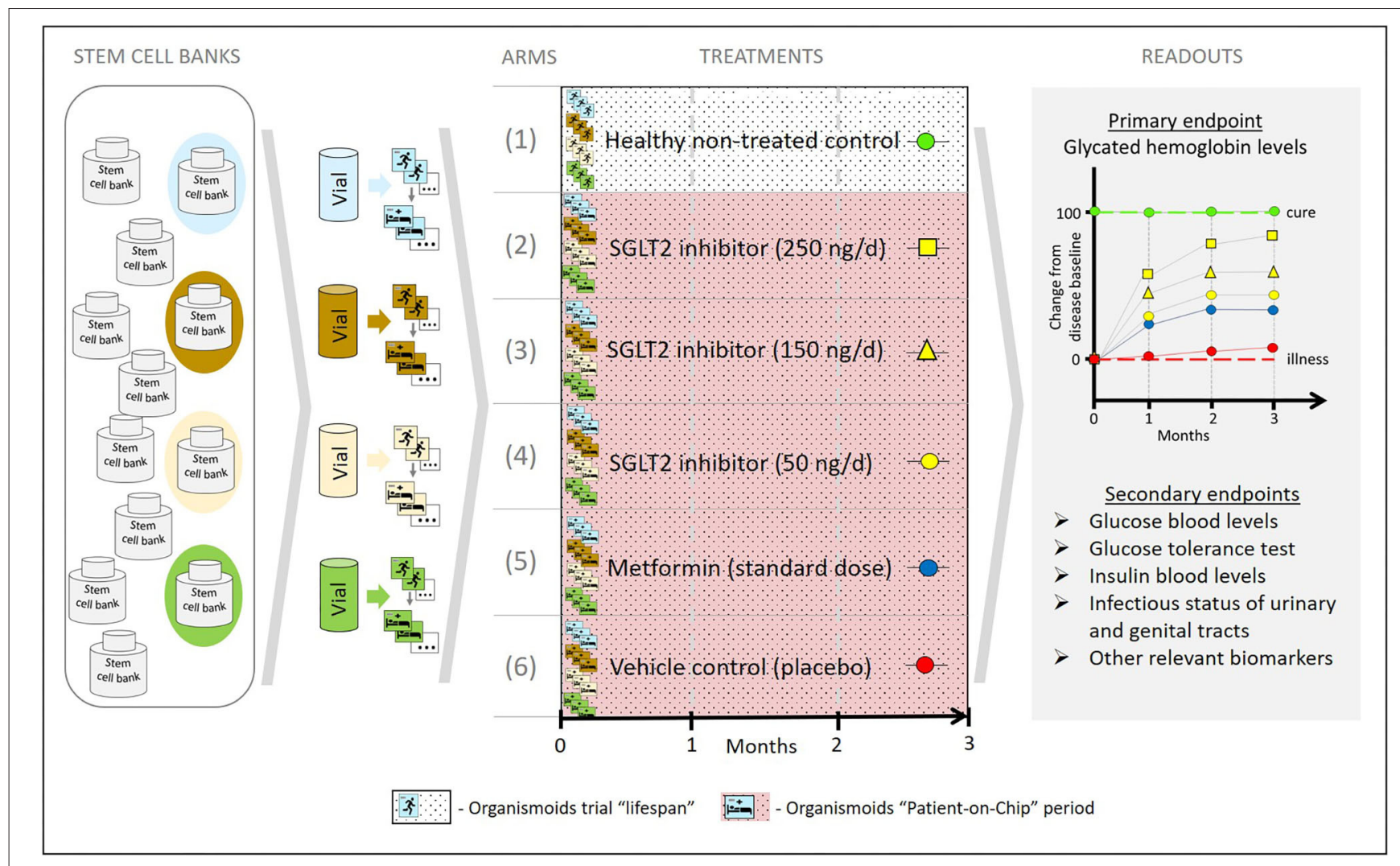

FIGURE 7 | A hypothetical example illustrating how the organismoid theory can be utilized to emulate clinical trials.

healthy homeostasis would allow one to conduct organismoidbased preclinical serial testing of medicines and advanced therapies in a setting emulating clinical trials with large trialspecific patient cohorts. In contrast to trials with patient cohorts, organismoid-based trials offer a number of crucial advantages. Figure 7 details these advantages by illustrating a hypothetical example of emulating a clinical trial of a hypothetical new sodium glucose transporter 2 (SGLT2) inhibitor to treat diabetes Type 2 utilizing an organismoid-based trial.

Stem cell samples from four donors representing a relevant diabetes patient cohort are collected from a global stem cell bank pool according to criteria equivalent to those of a clinical trial recruitment. A relevant number of healthy organismoids are produced from each of these four donor vials. Blue, brown, yellow and green colors indicate each individual donor background. Subsequently, following the principles of the organismoid theory, diabetic organismoids are generated, for example, through a high glucose diet. In order to evaluate a new SGLT2 inhibitor treatment, a 3 months' trial comprising six arms is conducted with 12 organismoids per arm (three biological repeats per arm and donor) and a daily oral-like administration of the respective medication. The control arms include the healthy recovery group (1) and the diseased untreated placebo group (2) which provide the readout for cure (green baseline) and for no change of disease status (red baseline), respectively. Furthermore, three doses of the new SGLT2 inhibitor are administered at 100,000-fold lower doses than expected in patients, due to the respective downscale of organismoid size in comparison to a human body. Readouts for arms (3), (4), and (5) illustrate the potential of the new monotherapy to change the disease status from baseline toward cure at doses corresponding to $25 \mathrm{mg}$ (yellow squares), $15 \mathrm{mg}$ (yellow triangles), and $5 \mathrm{mg}$ (yellow circles), respectively, per day and patient. A standard monotherapy arm hypothetically treated with metformin (blue circles) provides current standard care reference data. Arm (2) generates the most favorable treatment results in this hypothetical example.

The most prominent advantage is the fact that, for the first time in the history of drug development, organismoidbased trials on chips will include statistically relevant human autologous biological repeats of the patient's body and of the same individual's healthy body status. Due to the lack of any biological repeat for an individual patient and knowledge of their individual biological status at healthy homeostasis, clinical trials traditionally require large cohorts of patients. Therefore, the trials are divided into Phase 1, 2, and 3 and, unfortunately, can only approximate the pathobiology of an individual patient and their complete cure recovery status. Both aspects make the traditional clinical trial process a lengthy and incredibly costly and inefficient way of developing drugs and advanced therapies. "Clinical trials" on chips with healthy and diseased organismoids eliminate these two roadblocks. On the one hand, they allow the uniformity of inbred laboratory animal tests to be matched due to the genetic 
identity of each trial "participant" on an individual's organismoid level but with an entirely human background. On the other hand, the usage of organismoids of a variety of different individuals reflects the heterogeneity of patient cohorts in a clinical trial but with the advantage of statistically relevant biological repeats for each individual patient's organismoids.

Another obvious advantage of the organismoid approach is the independence from patient recruitment and hospital usage to conduct such trials. Given the existence of large PSC banks reflecting the genetic predisposition, gender and other categories relevant for the trials, an organismoid-based trial can be conducted at any time, anywhere in the world. Regarding the hypothetical example above, donor selection by diabetic predisposition, comparison of genetic ancestry and equal gender distribution might be interesting stem cell vial selection strategies.

The third advantage to mention is the flexibility regarding the trial size. The number of diseased organismoids (commonly referred to as "patients" on chips) which can be generated is theoretically unlimited. This allows the integration of pharmacokinetic aspects, finding of effective doses and combined safety and efficacy evaluation of a new chemical or biological entity in one and the same organismoid-based trial. Data which are currently generated in separate preclinical and clinical trials in laboratory animals, healthy volunteers and patients, such as the toxicity profile, the no-observed-adverse-effect-level, absorption and excretions rates, metabolite formation, the finding of effective doses, duration and scheduling of a new medication, can result from one organismoid-based trial. Our hypothetical case study to treat Type 2 diabetes could, for example, be easily extended to a larger dose range and a comparison of a single oral-like (this refers in organismoids to any administration to the apical intestine) daily administration with two doses a day. This would include a dose-dependent evaluation of efficacy while simultaneously observing the occurrence and severity of urinal or genital tract infections, well-known side effects of SGLT2 inhibitors. The definition of a therapeutic window for the use of the drug candidate in a respective patient cohort results from such an all-in-one trial, still at a preclinical candidate development stage.

Regarding both usage scenarios, we envisage that organismoids will contribute significantly to medical realworld big data collection from an individual's databases. This is due to the ability to generate unique reproducible data on microenvironmental disruption at the defined location of a first disease hit (e.g., tumor growth, virus replication) for each patient. The combination of organismoid and in silico approaches will further increase the predictive power for precise medications for large patient cohorts and reduce costs further.

Sophisticated in vitro cell culture work is usually connected in people's minds with high costs. One might speculate that the generation and processing of thousands of organismoids in a trial involves an astronomical budget because currently available MPSs are expensive both in disposable chips and operations. Here, the nature of organismoids-reflecting a self-sustainable human body-and economy of scale effects come into play. In the real world, a human body at rest can be sustained with a daily supply of about 2,000 kcal in proteins, carbohydrates and fat. This can be achieved in some poorer areas of the world for a single digit US dollar bill per person. Consequently, the daily feeding of 100,000 organismoids could be achieved for the same costs. The price of the consumable chips hosting the organismoids will predictively go down to the single dollar range as well, a downscale factor which has already been experienced with computer chips and human genome sequencing costs.

The socioeconomical dimension of the ability of organismoids to identify the best fitting medication for every individual patient and to radically cut costs and transform drug development is envisioned to be enormous. The same applies to the ethical dimension. Human MPS-based organismoids bear the potential to replace the majority of laboratory animal tests and Phase 1 and 2 clinical trials in human volunteers. They will reduce the number of Phase 3 clinical trial patients manifold. All of this will have a radically positive impact on both the patient's benefit and animal welfare on a global scale.

\section{PATIENT'S ORGANISMOIDS AND PATIENT-SPECIFIC T-CELL THERAPIES ON CHIPS-A PERFECT ALLIANCE TO CHALLENGE THE THEORY}

Advanced cell therapies, such as the autologous chimeric antigen receptor (CAR) T cell therapies Kymriah ${ }^{\mathrm{TM}}$ and Yescarta ${ }^{\mathrm{TM}}$, have recently proven their potential to cure former treatmentresistant tumor patients $(176,177)$. In addition to these two CAR$\mathrm{T}$ cell products approved in 2017 against hematologic tumors, several other CAR-T cell products have recently been approved. Numerous new cell therapy approaches are in the pipeline with CAR or transgenic T-cell receptors against a wide variety of tumors, infections and autoaggressive immune cells, or the use of regulatory $\mathrm{T}$ cells to restore immune balance in dominant undesired immune reactions (178). More than 1,000 clinical trials with immune cell products were registered worldwide at the end of 2020 (179).

This unprecedented efficacy in such areas of unmet medical need has spurred regulatory acceptance at the cost of standard safety testing procedures (180), which need to be generated retrospectively in follow-up studies of patients treated after therapy approval. That complies with the fact that a patient's response to a personalized cell therapy cannot be emulated pre-clinically in laboratory animal models because of their phylogenetic distance from the patient, the respective genotypic differences and the immunological mismatch. Similarly, a patient's responses cannot be predicted in conventional patientderived organoid cultures, due to the lack of their integration into a systemic organismal arrangement. Inter alia, the emulation of the intravenous delivery of the T-cell infusion to the target site and its interaction with other major organ sites are missing crucial factors to emulate T-cell therapies and their efficacy 
profile in patient-derived organoids precisely. As outlined earlier, the organismoid theory here provides an alternative solution overcoming any remaining obstacles.

\section{WHAT ORGANISMOIDS CANNOT AND SHOULD NOT DO}

According to organismoid theory, an organismoid cannot and should not emulate the empathy or consciousness (soul or mind, respectively) which are the major parts of the sociogenesis of a human individual. Consequently, it is not able to model a patient's psychiatric disorders. The dysfunction of a $300 \mathrm{~g}$ human heart muscle or hip fracture and its healing rely on biophysical properties, some of which cannot be represented on organismoids due to the mismatch of scale and the physics involved.

Ethical considerations are paramount for human society and are the basis for humanity. Organismoid theory, due to its nature, introduces a number of points which must be considered ethically. Development of the human embryo until a few centimeters in scale is one of the most crucial issues. Fertilization of a human egg and its subsequent embryonic development in an artificial environment (e.g., in vitro culture) is prohibited in many parts of the world. The authors of the organismoid theory would like to emphasize that their ethical paradigms extend beyond this. One should not use the concepts and principles of the organismoid theory to create a human or hybrid embryo and further develop and differentiate human or hybrid tissue from that. Other methods should be used to circumvent this part of ontogenesis. The individual's consent to donate tissue to create organismoids could be a good tool to prevent misuse in the areas mentioned at an early stage.

\section{CONCLUSION}

The organismoid theory presented here claims the ability to artificially recapitulate the ontogenesis of an individual's body in vitro, starting with a donor's stem cells and generating a defined number of identical healthy mature miniaturized body equivalents, termed organismoids, thereof. The theory further claims that such sets of donor-specific identical organismoids reflect a certain stage of that individual's healthy adulthood and can be used to simulate phases of disease and recovery relevant to that donor at a certain time in their lifespan. Modeling the individual's disease in a personalized diseased organismoid approach will provide a yet unmet realistic level of the patient's pathobiology and, consequently, provide an unprecedented tool for selecting precisely the right medicine, therapy schedule and dosing to cure the (diseased) individual.

Nature's principles of genetically and microenvironmentally encoded self-organization and maintenance of the smallest functional units of human organs and their integration into a cross talking and efficiently interacting system of blood perfusion and innervated organs are the blueprint for creating organismoids on chips. We envision them becoming the next level of emulation of human biology, providing the best possible approximation of the human counterpart. Organismoids will organically follow the organoid level of human biology in vitro, which, in recent years, has proven to enable the emulation of distinct functions of single tissues and organs at a miniaturized scale. Leveraging on what has been learnt from organoids, human organismoids will add the systemic innervation and supply of whole blood generated on-chip via a miniaturized physiology-based vascular and blood capillary network to the functional units of each organ equivalent. The local separation of the organotypic microenvironments of each organ equivalent from the common bloodstream by the endothelial cell layer will enable the separate organ-specific, genetically encoded and microenvironment-driven self-assembly of exact copies of the functional units of the different human organs on-chip. That, in turn, will enable the physiological cross talk of mature organ equivalents, leading to organismal on-chip homeostasis. Once established, organismoids will only require daily feeding with equivalents of digested food to emulate long-term, so-called self-sustained, body functionality on a chip.

We have illustrated that human organoid in vitro culture technologies and human single-organ chips produced within the last 10 years have provided vast evidence for the concept of artificial in vitro ontogenesis of single organ equivalents. Furthermore, human iPSC-derived multi-organ chips have furnished first indications of an accelerated artificial organ ontogenesis on chips. Finally, an ever-growing scientific literature on human disease modeling and treatment testing on human tissue chips points toward the capability of such microphysiological platforms to precisely emulate the pathobiology of a disease and the mode of action of a medicine or therapy when organismoids can be fully functionally established on MPSs. Major challenges for the further development of organ-on-a-chip systems are nervous innervation and the implementation of capillarization of the organoids, which also allows the migration of cells, especially immune cells, into the tissue.

We have enrolled the two concepts underlying the organismoid theory and detailed the principles of how to generate and use organismoids for personalized precision medicine.

The prime socioeconomic driver for challenging the organismoid theory is an urgently needed paradigm shift in advanced therapy and drug development for the much faster implementation of affordable advanced therapies and precision medicines into real-world healthcare to cure patients with unmet medical needs. The prime ethical driver is the replacement of the majority of laboratory animal tests and Phase 1 clinical trials on healthy volunteers in the drug development cycle and the shift from treating symptoms toward a curing paradigm for chronic diseases on a global healthcare level. Therefore, we have proposed accelerating the establishment of human 
organismoids by their first proof of concept studies in predicting the outcome, dosing and scheduling of advanced autologous T-cell therapies.

\section{OUTLOOK}

The MPS community envisions the first proof-of-theory for organismoids to occur within a decade, tackling the radical improvements for the healthcare system described. However, major milestones, such as the interconnection of organ equivalents by a biological vasculature and lymphatics, organ innervation, integration of microbiota, an enterohepatic circulation and, finally, a human-relevant degree of hematopoiesis need to be achieved to accomplish this aim. Above and beyond healthcare, human organismoids, once established, will provide a unique tool for the next level of basic discoveries in the life science of humans. The stable long-term functionality on such a tiny scale and the arbitrary variability in gender, age and genetic background of individual body organismoids will enable previously unimagined insights into human biology. We foresee the use of organismoids for predicting optimized diets, including the adaptation of the microbiome, on an individual or subpopulation level. The development of optimized functional synthetic food to feed the global population beyond 2,100 can be effectively guided by organismoids. The latter will serve as sensitive personalized biological sensors for environmental pollution in air and drinking water and identify potential hypersensitivity risks for their donors. Finally, they bear the potential to become the prime tool for the personalized prediction of measures to ensure the longevity of their respective donors.

\section{REFERENCES}

1. Featherman DL, Lerner RM. Ontogenesis and sociogenesis: problematics for theory and research about development and socialization across the lifespan. Am Sociol Rev. (1985) 50:659-76. doi: 10.2307/209 5380

2. von Bartheld CS, Bahney J, Herculano-Houzel S. The search for true numbers of neurons and glial cells in the human brain: a review of 150 years of cell counting. J Comp Neurol. (2016) 524:3865-95. doi: 10.1002/cne. 24040

3. Kastellakis G, Poirazi P. Synaptic clustering and memory formation. Front Mol Neurosci. (2019) 12:1-13. doi: 10.3389/fnmol.2019.00300

4. Marx U, Sandig V. Drug Testing in vitro: Breakthroughs and Trends in Cell Culture Technology. Weinheim: WILEY-VCH (2007). p. 275.

5. Marx U, Walles H, Hoffmann S, Lindner G, Horland R, Sonntag $\mathrm{F}$, et al. "Human-on-a-chip" developments: a translational cutting-edge alternative to systemic safety assessment and efficiency evaluation of substances in laboratory animals and man. Altern Lab Anim. (2012) 40:23557. doi: 10.1177/026119291204000504

6. $\mathrm{Xu} \mathrm{H}, \mathrm{Wu}$ J, Chu C-C, Shuler ML. Development of disposable PDMS micro cell culture analog devices with photopolymerizable hydrogel encapsulating living cells. Biomed Microdev. (2012) 14:409-18. doi: 10.1007/s10544-011-9617-4

7. Ingber DE, Whitesides GM. Lab on a chip: United States of America. Lab Chip. (2012) 12:2089-90. doi: 10.1039/c2lc90052a

\section{DATA AVAILABILITY STATEMENT}

Publicly available datasets were analyzed in this study. This data can be found here: https://www.ncbi.nlm.nih.gov/pmc/articles/ PMC6745596/.

\section{AUTHOR CONTRIBUTIONS}

All authors listed have made a substantial, direct and intellectual contribution to the work, drafted the manuscript, revised it and approved it for publication. UM and RL developed the concept. $\mathrm{RD}, \mathrm{LK}$, and $\mathrm{AW}$ performed, analyzed and interpreted experiments relating to Figure 3. LK, APR, and E-MD performed, analyzed and interpreted experiments relating to Figure 4.

\section{FUNDING}

Part of this work was supported by the German Federal Ministry of Education and Research (GO-Bio 3B grant agreement No. 031B0062 and Alternativmethoden - Verbund grant agreement No. 031L0099A) and the European Union's Horizon 2020 research and innovation program (RESTORE grant agreement No. 820292).

\section{ACKNOWLEDGMENTS}

We wish to thank Philip Saunders for orthographical support with the manuscript. We thank Conor Parks, Surya Kotha, Kainat Khan, and Gareth Maglennon for the generation of cells and their identification in Figure 3. We thank Nora Huck for helping with Figure 5.

8. Marx U, Akabane T, Andersson TB, Baker E, Beilmann M, Beken S, et al. Biology-inspired microphysiological systems to advance patient benefit and animal welfare in drug development. ALTEX. (2020) 37:36594. doi: 10.14573/altex.2001241

9. Dehne E, Marx U. The universal physiological template a system to advance medicines. Curr Opin Toxicol. (2020) 23-24:1-5. doi: 10.1016/j.cotox.2020.02.002

10. Beilmann M, Boonen H, Czich A, Dear G, Hewitt P, Mow T, et al. Optimizing drug discovery by investigative toxicology: current and future trends. ALTEX. (2019) 36:289-313. doi: 10.14573/altex.1808181

11. Takahashi T. Organoids for drug discovery and personalized medicine. Annu Rev Pharmacol Toxicol. (2019) 59:447-62. doi: 10.1146/annurev-pharmtox-010818-021108

12. Kopper O, de Witte CJ, Lõhmussaar K, Valle-Inclan JE, Hami $\mathrm{N}$, Kester L, et al. An organoid platform for ovarian cancer captures intra- and interpatient heterogeneity. Nat Med. (2019) 25:838-49. doi: 10.1136/ijgc-2019-ESGO.182

13. Hofer M, Lutolf MP. Engineering organoids. Nat Rev Mater. (2021) 6:40220. doi: 10.1038/s41578-021-00279-y

14. Homan KA, Gupta N, Kroll KT, Kolesky DB, Skylar-Scott M, Miyoshi T, et al. Flow-enhanced vascularization and maturation of kidney organoids in vitro. Nat Methods. (2019) 16:255-62. doi: 10.1038/s41592-019-0325-y

15. Pham MT, Pollock KM, Rose MD, Cary WA, Stewart HR, Zhou P, et al. Generation of human vascularized brain organoids. Neuroreport. (2018) 29:588-93. doi: 10.1097/WNR.0000000000001014 
16. Wörsdörfer P, Dalda N, Kern A, Krüger S, Wagner N, Kwok CK, et al. Generation of complex human organoid models including vascular networks by incorporation of mesodermal progenitor cells. Sci Rep. (2019) 9:15663. doi: 10.1038/s41598-019-52204-7

17. Schutgens F, Clevers H. Human organoids: tools for understanding biology and treating diseases. Annu Rev Pathol. (2020) 15:21134. doi: 10.1146/annurev-pathmechdis-012419-032611

18. Lee J, Rabbani CC, Gao H, Steinhart MR, Woodruff BM, Pflum ZE, et al. Hair-bearing human skin generated entirely from pluripotent stem cells. Nature. (2020) 582:399-404. doi: 10.1038/s41586-020-2352-3

19. Sloan SA, Andersen J, Paśca AM, Birey F, Paśca SP. Generation and assembly of human brain region-specific three-dimensional cultures. Nat Protoc. (2018) 13:2062-85. doi: 10.1038/s41596-018-0032-7

20. Giandomenico SL, Sutcliffe M, Lancaster MA. Generation and long-term culture of advanced cerebral organoids for studying later stages of neural development. Nat Protoc. (2021) 16:579-602. doi: 10.1038/s41596-020-00433-w

21. Rosowski J, Bräunig J, Amler A, Strietzel FP, Lauster R, Rosowski M. Emulating the early phases of human tooth development in vitro. Sci Rep. (2019) 9:7057. doi: 10.1038/s41598-019-43468-0

22. Lindner G, Horland R, Wagner I, Ataç B, Lauster R. De novo formation and ultra-structural characterization of a fiber-producing human hair follicle equivalent in vitro. J Biotechnol. (2011) 152:10812. doi: 10.1016/j.jbiotec.2011.01.019

23. Kim J, Koo B, Knoblich JA. Human organoids: model systems for human biology and medicine. Nat Rev Mol Cell Biol. (2020) 21:57184. doi: 10.1038/s41580-020-0259-3

24. McCauley HA, Wells JM. Pluripotent stem cell-derived organoids: using principles of developmental biology to grow human tissues in a dish. Development. (2017) 144:958-62. doi: 10.1242/dev.140731

25. Takebe T, Wells JM. Organoids by design. Science. (2019) 364:9569. doi: 10.1126/science.aaw7567

26. Wimmer RA, Leopoldi A, Aichinger M, Wick N, Hantusch B, Novatchkova $\mathrm{M}$, et al. Human blood vessel organoids as a model of diabetic vasculopathy. Nature. (2019) 565:505-10. doi: 10.1038/s41586-018-0858-8

27. Lancaster MA, Renner M, Martin CA, Wenzel D, Bicknell LS, Hurles $\mathrm{ME}$, et al. Cerebral organoids model human brain development and microcephaly. Nature. (2013) 501:373-9. doi: 10.1038/nature12517

28. Quadrato G, Nguyen T, Macosko EZ, Sherwood JL, Yang SM, Berger DR, et al. Cell diversity and network dynamics in photosensitive human brain organoids. Nature. (2017) 545:48-53. doi: 10.1038/nature22047

29. Renner M, Lancaster MA, Bian S, Choi H, Ku T, Peer A, et al. Self-organized developmental patterning and differentiation in cerebral organoids. $E M B O$ J. (2017) 36:1316-29. doi: 10.15252/embj.201694700

30. Ormel PR, Vieira de Sá R, van Bodegraven EJ, Karst H, Harschnitz O, Sneeboer MAM, et al. Microglia innately develop within cerebral organoids. Nat Commun. (2018) 9:4167. doi: 10.1038/s41467-018-06684-2

31. Giandomenico SL, Mierau SB, Gibbons GM, Wenger LMD, Masullo $\mathrm{L}$, Sit $\mathrm{T}$, et al. Cerebral organoids at the air-liquid interface generate diverse nerve tracts with functional output. Nat Neurosci. (2019) 22:66979. doi: 10.1038/s41593-019-0350-2

32. Pasca AM, Sloan SA, Clarke LE, Tian Y, Makinson CD, Huber N, et al. Functional cortical neurons and astrocytes from human pluripotent stem cells in 3D culture. Nat Methods. (2015) 12:671-8. doi: 10.1038/nmeth.3415

33. Qian X, Nguyen HN, Song MM, Hadiono C, Ogden SC, Hammack C, et al. Brain-region-specific organoids using mini-bioreactors for modeling ZIKV exposure. Cell. (2016) 165:1238-54. doi: 10.1016/j.cell.2016.04.032

34. Trujillo CA, Gao R, Negraes PD, Gu J, Buchanan J, Preissl S, et al. Complex oscillatory waves emerging from cortical organoids model early human brain network development. Cell Stem Cell. (2019) 25:55869.e7 doi: 10.1016/j.stem.2019.08.002

35. Rigamonti A, Repetti GG, Sun C, Price FD, Reny DC, Rapino F, et al. Largescale production of mature neurons from human pluripotent stem cells in a three-dimensional suspension culture system. Stem Cell Rep. (2016) 6:993-1008. doi: 10.1016/j.stemcr.2016.05.010

36. Eura N, Matsui TK, Luginbühl J, Matsubayashi M, Nanaura H, Shiota T, et al. Brainstem organoids from human pluripotent stem cells. Front Neurosci. (2020) 14:538. doi: 10.3389/fnins.2020.00538
37. Muguruma K, Nishiyama A, Kawakami H, Hashimoto K, Sasai Y. Self-organization of polarized cerebellar tissue in 3D culture of human pluripotent stem cells. Cell Rep. (2015) 10:537-50. doi: 10.1016/j.celrep.2014.12.051

38. Monzel AS, Smits LM, Hemmer K, Hachi S, Moreno EL, van Wuellen T, et al. Derivation of human midbrain-specific organoids from neuroepithelial stem cells. Stem Cell Rep. (2017) 8:1144-54. doi: 10.1016/j.stemcr.2017.03.010

39. Xiang Y, Tanaka Y, Cakir B, Patterson B, Kim K, Sun P, et al. hESC-derived thalamic organoids form reciprocal projections when fused with cortical organoids. Cell Stem Cell. (2019) 24:487-97. doi: 10.1016/j.stem.2018.12.015

40. Ogura T, Sakaguchi H, Miyamoto S, Takahashi J. Three-dimensional induction of dorsal, intermediate and ventral spinal cord tissues from human pluripotent stem cells. Development. (2018) 145:dev162214. doi: 10.1242/dev.162214

41. Sakaguchi H, Kadoshima T, Soen M, Narii N, Ishida Y, Ohgushi M, et al. Generation of functional hippocampal neurons from self-organizing human embryonic stem cell-derived dorsomedial telencephalic tissue. Nat Commun. (2015) 6:8896. doi: 10.1038/ncomms9896

42. Camp JG, Badsha F, Florio M, Kanton S, Gerber T, Wilsch-Bräuninger M, et al. Human cerebral organoids recapitulate gene expression programs of fetal neocortex development. Proc Natl Acad Sci USA. (2015) 112:156727. doi: 10.1073/pnas.1520760112

43. Wu F, Wu D, Ren Y, Huang Y, Feng B, Zhao N, et al. Generation of hepatobiliary organoids from human induced pluripotent stem cells. $J$ Hepatol. (2019) 70:1145-58. doi: 10.1016/j.jhep.2018.12.028

44. Wu D, Chen X, Sheng Q, Chen W, Zhang Y, Wu F. Production of functional hepatobiliary organoids from human pluripotent stem cells. Int J Stem Cells. (2021) 14:119-26. doi: 10.15283/ijsc20152

45. Huch M, Gehart H, Van Boxtel R, Hamer K, Blokzijl F, Verstegen MMA, et al. Long-term culture of genome-stable bipotent stem cells from adult human liver. Cell. (2015) 160:299-312. doi: 10.1016/j.cell.2014. 11.050

46. Hu H, Gehart H, Artegiani B, Löpez-Iglesias C, Dekkers F, Basak O, et al. Long-term expansion of functional mouse and human hepatocytes as 3D organoids. Cell. (2018) 175:1591-606.e19. doi: 10.1016/j.cell.2018. 11.013

47. Takebe T, Zhang R-R, Koike H, Kimura M, Yoshizawa E, Enomura $\mathrm{M}$, et al. Generation of a vascularized and functional human liver from an iPSC-derived organ bud transplant. Nat Protoc. (2014) 9:396409. doi: 10.1038/nprot.2014.020

48. Camp JG, Sekine K, Gerber T, Loeffler-Wirth H, Binder H, Gac M, et al. Multilineage communication regulates human liver bud development from pluripotency. Nature. (2017) 546:533-8. doi: 10.1038/nature2 2796

49. Ang LT, Tan AKY, Autio MI, Goh SH, Choo SH, Lee KL, et al. A roadmap for human liver differentiation from pluripotent stem cells. Cell Rep. (2018) 22:2190-205. doi: 10.1016/j.celrep.2018.01.087

50. Takebe T, Sekine K, Kimura M, Yoshizawa E, Ayano S, Koido $\mathrm{M}$, et al. Massive and reproducible production of liver buds entirely from human pluripotent stem cells. Cell Rep. (2017) 21:2661-70. doi: 10.1016/j.celrep.2017.11.005

51. Sampaziotis F, De Brito MC, Madrigal P, Bertero A, Saeb-Parsy K, Soares FAC, et al. Cholangiocytes derived from human induced pluripotent stem cells for disease modeling and drug validation. Nat Biotechnol. (2015) 33:845-52. doi: 10.1038/nbt.3275

52. Ogawa M, Ogawa S, Bear CE, Ahmadi S, Chin S, Li B, et al. Directed differentiation of cholangiocytes from human pluripotent stem cells. Nat Biotechnol. (2015) 33:853-61. doi: 10.1038/nbt.3294

53. Mun SJ, Lee J, Chung KS, Son MY, Son MJ. Effect of microbial short-chain fatty acids on CYP3A4-mediated metabolic activation of human pluripotent stem cell-derived liver organoids. Cells. (2021) 10:126. doi: 10.3390/cells10010126

54. Mun SJ, Ryu JS, Lee MO, Son YS, Oh SJ, Cho HS, et al. Generation of expandable human pluripotent stem cell-derived hepatocyte-like liver organoids. J Hepatol. (2019) 71:970-85. doi: 10.1016/j.jhep.2019. 06.030

55. Rashidi H, Luu NT, Alwahsh SM, Ginai M, Alhaque S, Dong H, et al. 3D human liver tissue from pluripotent stem cells displays stable phenotype in 
vitro and supports compromised liver function in vivo. Arch Toxicol. (2018) 92:3117-29. doi: 10.1007/s00204-018-2280-2

56. Huch M, Dorrell C, Boj SF, Van Es JH, Li VSW, Van De Wetering M, et al. In vitro expansion of single Lgr5 + liver stem cells induced by Wnt-driven regeneration. Nature. (2013) 494:247-50. doi: 10.1038/nature 11826

57. Kurmann AA, Serra M, Hawkins F, Rankin SA, Mori M, Astapova I, et al. Regeneration of thyroid function by transplantation of differentiated pluripotent stem cells. Cell Stem Cell. (2015) 17:527-42. doi: 10.1016/j.stem.2015.09.004

58. Huang L, Desai R, Conrad DN, Leite NC, Akshinthala D, Lim CM, et al. Commitment and oncogene-induced plasticity of human stem cell-derived pancreatic acinar and ductal organoids. Cell Stem Cell. (2021) 28:1090104.e6. doi: 10.1016/j.stem.2021.03.022

59. Huang L, Holtzinger A, Jagan I, Begora M, Lohse I, Ngai N, et al. Ductal pancreatic cancer modeling and drug screening using human pluripotent stem cell- and patient-derived tumor organoids. Nat Med. (2015) 21:136471. doi: $10.1038 / \mathrm{nm} .3973$

60. Hohwieler M, Illing A, Hermann PC, Mayer T, Stockmann M, Perkhofer L, et al. Human pluripotent stem cell-derived acinar/ductal organoids generate human pancreas upon orthotopic transplantation and allow disease modelling. Gut. (2017) 66:473-86. doi: 10.1136/gutjnl-2016-312423

61. Gabriel E, Albanna W, Pasquini G, Ramani A, Josipovic N, Hescheler J, et al. Human brain organoids assemble functionally integrated bilateral optic vesicles. bioRxiv [Preprint]. (2021) 1-67. doi: 10.1101/2021.03.30.437506

62. Nakano T, Ando S, Takata N, Kawada M, Muguruma K, Sekiguchi K, et al. Self-formation of optic cups and storable stratified neural retina from human ESCs. Cell Stem Cell. (2012) 10:771-85. doi: 10.1016/j.stem.2012.05.009

63. Phillips MJ, Wallace KA, Dickerson SJ, Miller MJ, Verhoeven AD, Martin $\mathrm{JM}$, et al. Blood-derived human iPS cells generate optic vesicle-like structures with the capacity to form retinal laminae and develop synapses. Invest Ophthalmol Vis Sci. (2012) 53:2007-19. doi: 10.1167/iovs.11-9313

64. Reichman S, Terray A, Slembrouck A, Nanteau C, Orieux G, Habeler W, et al. From confluent human iPS cells to self-forming neural retina and retinal pigmented epithelium. Proc Natl Acad Sci USA. (2014) 111:851823. doi: $10.1073 /$ pnas.1324212111

65. Zhong X, Gutierrez C, Xue T, Hampton C, Vergara MN, Cao $\mathrm{LH}$, et al. Generation of three-dimensional retinal tissue with functional photoreceptors from human iPSCs. Nat Commun. (2014) 5:4047. doi: $10.1038 /$ ncomms5047

66. Capowski EE, Samimi K, Mayerl SJ, Phillips MJ, Pinilla I, Howden $\mathrm{SE}$, et al. Reproducibility and staging of 3D human retinal organoids across multiple pluripotent stem cell lines. Development. (2019) 146:dev171686. doi: 10.1242/dev.171686

67. Sato T, Vries RG, Snippert HJ, Van De Wetering M, Barker N, Stange DE, et al. Single Lgr5 stem cells build crypt-villus structures in vitro without a mesenchymal niche. Nature. (2009) 459:262-5. doi: 10.1038/nature07935

68. Sato T, Stange DE, Ferrante M, Vries RGJ, Van Es JH, Van Den Brink $\mathrm{S}$, et al. Long-term expansion of epithelial organoids from human colon, adenoma, adenocarcinoma, and Barrett's epithelium. Gastroenterology. (2011) 141:1762-72. doi: 10.1053/j.gastro.2011.07.050

69. Spence JR, Mayhew CN, Rankin SA, Kuhar M, Vallance E, Tolle K, et al. Directed differentiation of human pluripotent stem cells into intestinal tissue in vitro. Nature. (2011) 470:105-9. doi: 10.1038/nature09691

70. Workman MJ, Mahe MM, Trisno S, Poling HM, Watson CL, Sundaram $\mathrm{N}$, et al. Engineered human pluripotent-stem-cell-derived intestinal tissues with a functional enteric nervous system. Nat Med. (2017) 23:4959. doi: $10.1038 / \mathrm{nm} .4233$

71. Tsai YH, Nattiv R, Dedhia PH, Nagy MS, Chin AM, Thomson M, et al. In vitro patterning of pluripotent stem cell-derived intestine recapitulates in vivo human development. Development. (2017) 144:104555. doi: 10.1242/dev.138453

72. Barker N, Huch M, Kujala $P$, van de Wetering $M$, Snippert HJ, van Es JH, et al. Lgr5+ve stem cells drive self-renewal in the stomach and build long-lived gastric units in vitro. Cell Stem Cell. (2010) 6:2536. doi: 10.1016/j.stem.2009.11.013

73. Bartfeld S, Bayram T, Van De Wetering M, Huch M, Begthel H, Kujala $\mathrm{P}$, et al. In vitro expansion of human gastric epithelial stem cells and their responses to bacterial infection. Gastroenterology. (2015) 148:12636.e6. doi: 10.1053/j.gastro.2014.09.042

74. McCracken KW, Catá EM, Crawford CM, Sinagoga KL, Schumacher $\mathrm{M}$, Rockich $\mathrm{BE}$, et al. Modelling human development and disease in pluripotent stem-cell-derived gastric organoids. Nature. (2014) 516:4004. doi: $10.1038 /$ nature 13863

75. McCracken KW, Aihara E, Martin B, Crawford CM, Broda T, Treguier J, et al. $\mathrm{Wnt} / \beta$-catenin promotes gastric fundus specification in mice and humans. Nature. (2017) 541:182-7. doi: 10.1038/nature21021

76. Taguchi A, Kaku Y, Ohmori T, Sharmin S, Ogawa M, Sasaki H, et al. Redefining the in vivo origin of metanephric nephron progenitors enables generation of complex kidney structures from pluripotent stem cells. Cell Stem Cell. (2014) 14:53-67. doi: 10.1016/j.stem.2013.11.010

77. Takasato M, Er PX, Becroft M, Vanslambrouck JM, Stanley EG, Elefanty AG, et al. Directing human embryonic stem cell differentiation towards a renal lineage generates a self-organizing kidney. Nat Cell Biol. (2014) 16:118-26. doi: 10.1038/ncb2894

78. Takasato M, Er PX, Chiu HS, Maier B, Baillie GJ, Ferguson C, et al. Kidney organoids from human iPS cells contain multiple lineages and model human nephrogenesis. Nature. (2015) 526:564-8. doi: 10.1038/nature15695

79. Taguchi A, Nishinakamura R. Higher-order kidney organogenesis from pluripotent stem cells. Cell Stem Cell. (2017) 21:73046.e6. doi: 10.1016/j.stem.2017.10.011

80. Morizane R, Lam AQ, Freedman BS, Kishi S, Valerius MT, Bonventre J V. Nephron organoids derived from human pluripotent stem cells model kidney development and injury. Nat Biotechnol. (2015) 33:1193200. doi: 10.1038/nbt.3392

81. Freedman BS, Brooks CR, Lam AQ, Fu H, Morizane R, Agrawal V, et al. Modelling kidney disease with CRISPR-mutant kidney organoids derived from human pluripotent epiblast spheroids. Nat Commun. (2015) 6:8715. doi: $10.1038 /$ ncomms 9715

82. Nikolić MZ, Caritg O, Jeng Q, Johnson JA, Sun D, Howell KJ, et al. Human embryonic lung epithelial tips are multipotent progenitors that can be expanded in vitro as long-term self-renewing organoids. Elife. (2017) 6:e26575. doi: 10.7554/eLife.26575

83. Sachs N, Papaspyropoulos A, Zomer-van Ommen DD, Heo I, Böttinger L, Klay $\mathrm{D}$, et al. Long-term expanding human airway organoids for disease modeling. EMBO J. (2019) 38:e100300. doi: 10.15252/embj.2018100300

84. Wong AP, Bear CE, Chin S, Pasceri P, Thompson TO, Huan LJ, et al. Directed differentiation of human pluripotent stem cells into mature airway epithelia expressing functional CFTR protein. Nat Biotechnol. (2012) 30:87682. doi: $10.1038 /$ nbt. 2328

85. Dye BR, Hill DR, Ferguson MA, Tsai YH, Nagy MS, Dyal R, et al. In vitro generation of human pluripotent stem cell derived lung organoids. Elife. (2015) 4:e05098. doi: 10.7554/eLife.05098

86. Chen YW, Huang SX, De Carvalho ALRT, Ho SH, Islam MN, Volpi S, et al. A three-dimensional model of human lung development and disease from pluripotent stem cells. Nat Cell Biol. (2017) 19:542-9. doi: 10.1038/ncb3510

87. Dye BR, Dedhia PH, Miller AJ, Nagy MS, White ES, Shea LD, et al. A bioengineered niche promotes in vivo engraftment and maturation of pluripotent stem cell derived human lung organoids. Elife. (2016) 5:e19732. doi: 10.7554/eLife.19732.023

88. Itoh M, Umegaki-Arao N, Guo Z, Liu L, Higgins C a., Christiano AM. Generation of 3D skin equivalents fully reconstituted from human induced pluripotent stem cells (iPSCs). PLOS ONE. (2013) 8:e77673. doi: 10.1371/journal.pone.0077673

89. Kim Y, Park N, Rim YA, Nam Y, Jung H, Lee K, et al. Establishment of a complex skin structure via layered co-culture of keratinocytes and fibroblasts derived from induced pluripotent stem cells. Stem Cell Res Ther. (2018) 9:217. doi: 10.1186/s13287-018-0958-2

90. Kehat I, Kenyagin-Karsenti D, Snir M, Segev H, Amit M, Gepstein A, et al. Human embryonic stem cells can differentiate into myocytes with structural and functional properties of cardiomyocytes. J Clin Invest. (2001) 108:407-14. doi: 10.1172/JCI200112131

91. Zhang J, Wilson GF, Soerens AG, Koonce CH, Yu J, Palecek SP, et al. Functional cardiomyocytes derived from human induced pluripotent stem cells. Circ Res. (2009) 104:e30-41. doi: 10.1161/CIRCRESAHA.108. 192237 
92. Laflamme MA, Chen KY, Naumova A V, Muskheli V, Fugate JA, Dupras SK, et al. Cardiomyocytes derived from human embryonic stem cells in pro-survival factors enhance function of infarcted rat hearts. Nat Biotechnol. (2007) 25:1015-24. doi: 10.1038/nbt1327

93. Lian X, Hsiao C, Wilson G, Zhu K, Hazeltine LB, Azarin SM, et al. Robust cardiomyocyte differentiation from human pluripotent stem cells via temporal modulation of canonical Wnt signaling. Proc Natl Acad Sci USA. (2012) 109:E1848-57. doi: 10.1073/pnas.1200250109

94. Burridge PW, Matsa E, Shukla P, Lin ZC, Churko JM, Ebert AD, et al. Chemically defined generation of human cardiomyocytes. Nat Methods. (2014) 11:855-60. doi: 10.1038/nmeth.2999

95. Linnemann JR, Miura H, Meixner LK, Irmler M, Kloos UJ, Hirschi B, et al. Quantification of regenerative potential in primary human mammary epithelial cells. Development. (2015) 142:3239-51. doi: 10.1242/dev.12 3554

96. Qu Y, Han B, Gao B, Bose S, Gong Y, Wawrowsky K, et al. Differentiation of human induced pluripotent stem cells to mammary-like organoids. Stem Cell Reports. (2017) 8:205-15. doi: 10.1016/j.stemcr.2016.12.023

97. Karthaus WR, Iaquinta PJ, Drost J, Gracanin A, Van Boxtel R, Wongvipat J, et al. Identification of multipotent luminal progenitor cells in human prostate organoid cultures. Cell. (2014) 159:163-75. doi: 10.1016/j.cell.2014.08.017

98. Drost J, Karthaus WR, Gao D, Driehuis E, Sawyers CL, Chen Y, et al. Organoid culture systems for prostate epithelial and cancer tissue. Nat Protoc. (2016) 11:347-58. doi: 10.1038/nprot.2016.006

99. Höfner T, Eisen C, Klein C, Rigo-Watermeier T, Goeppinger SM, Jauch A, et al. Defined conditions for the isolation and expansion of basal prostate progenitor cells of mouse and human origin. Stem Cell Reports. (2015) 4:503-18. doi: 10.1016/j.stemcr.2015.01.015

100. Carrel A. On the permanent life of tissues outside of the organism. J Exp Med. (1912) 15:516-28. doi: 10.1084/jem.15.5.516

101. Azizoglu DB, Cleaver O. Blood vessel crosstalk during organogenesis - focus on pancreas and endothelial cells. Wiley Interdiscip Rev Dev Biol. (2016) 5:598-617. doi: 10.1002/wdev.240

102. van den Berg CW, Ritsma L, Avramut MC, Wiersma LE, Leuning G, Lievers E, et al. Renal subcapsular transplantation of PSCderived kidney organoids induces neo-vasculogenesis and significant glomerular and tubular maturation in vivo. Stem Cell Rep. (2018) 10:751-65. doi: 10.1016/j.stemcr.2018.01.041

103. Takebe T, Sekine K, Enomura M, Koike H, Kimura M, Ogaeri T, et al. Vascularized and functional human liver from an iPSC-derived organ bud transplant. Nature. (2013) 499:481-4. doi: 10.1038/nature12271

104. Winkelman MA, Koppes AN, Koppes RA, Dai G. Bioengineering the neurovascular niche to study the interaction of neural stem cells and endothelial cells. APL Bioeng. (2021) 5:011507. doi: 10.1063/5.0027211

105. Zhang B, Radisic M. Organ-on-a-Chip devices advance to market. Lab Chip. (2017) 17:2395-420. doi: 10.1039/C6LC01554A

106. Marx U, Andersson TB, Bahinski A, Beilmann M, Beken S, Cassee FR, et al. Biology-inspired microphysiological system approaches to solve the prediction dilemma of substance testing. ALTEX. (2016) 33:272321. doi: 10.14573 /altex.1603161

107. Wang YI, Carmona C, Hickman JJ, Shuler ML. Multiorgan microphysiological systems for drug development: strategies, advances, and challenges. Adv Healthc Mater. (2018) 7:1-54. doi: 10.1002/adhm.201701000

108. Ronaldson-Bouchard K, Vunjak-Novakovic G. Organs-on-a-chip: a fast track for engineered human tissues in drug development. Cell Stem Cell. (2018) 22:31024. doi: 10.1016/j.stem.2018.02.011

109. Low LA, Mummery C, Berridge BR, Austin CP, Tagle DA. Organson-chips: into the next decade. Nat Rev Drug Discov. (2020) 20:34561. doi: 10.1038/s41573-020-0079-3

110. Ma C, Peng Y, Li H, Chen W. Organ-on-a-chip: a new paradigm for drug development. Trends Pharmacol Sci. (2021) 42:119-33. doi: 10.1016/j.tips.2020.11.009

111. de Mello CPP, Rumsey J, Slaughter V, Hickman JJ. A human-on-a-chip approach to tackling rare diseases. Drug Discov Today. (2019) 24:213951. doi: 10.1016/j.drudis.2019.08.001

112. Wang Y, Wang L, Zhu Y, Qin J. Human brain organoid-on-achip to model prenatal nicotine exposure. Lab Chip. (2018) 18:85160. doi: 10.1039/C7LC01084B
113. Wang Y, Wang L, Guo Y, Zhu Y, Qin J. Engineering stem cell-derived 3D brain organoids in a perfusable organ-on-a-chip system. RSC Adv. (2018) 8:1677-85. doi: 10.1039/C7RA11714K

114. Rifes P, Isaksson M, Rathore GS, Aldrin-Kirk P, Møller OK, Barzaghi G, et al. Modeling neural tube development by differentiation of human embryonic stem cells in a microfluidic WNT gradient. Nat Biotechnol. (2020) 38:126573. doi: 10.1038/s41587-020-0525-0

115. Sances S, Ho R, Vatine G, West D, Laperle A, Meyer A, et al. Human iPSC-derived endothelial cells and microengineered organchip enhance neuronal development. Stem Cell Rep. (2018) 10:122236. doi: 10.1016/j.stemcr.2018.02.012

116. Vatine GD, Barrile R, Workman MJ, Sances S, Barriga BK, Rahnama M, et al. Human iPSC-derived blood-brain barrier chips enable disease modeling and personalized medicine applications. Cell Stem Cell. (2019) 24:9951005.e6. doi: 10.1016/j.stem.2019.05.011

117. Liu L, Koo Y, Russell T, Gay E, Li Y, Yun Y. Three-dimensional brain-onchip model using human iPSC-derived GABAergic neurons and astrocytes: Butyrylcholinesterase posttreatment for acute malathion exposure. PLoS ONE. (2020) 15:e0230335. doi: 10.1371/journal.pone.0230335

118. Achberger K, Probst C, Haderspeck JC, Bolz S, Rogal J, Chuchuy J, et al. Merging organoid and organ-on-a-chip technology to generate complex multi-layer tissue models in a human retina-on-a-chip platform. Elife. (2019) 8:e46188. doi: 10.7554/eLife.46188

119. Wang $\mathrm{Y}$, Wang $\mathrm{H}$, Deng $\mathrm{P}$, Chen $\mathrm{W}$, Guo $\mathrm{Y}$, Tao $\mathrm{T}$, et al. In situ differentiation and generation of functional liver organoids from human iPSCs in a 3D perfusable chip system. Lab Chip. (2018) 18:360616. doi: 10.1039/C8LC00869H

120. Michielin F, Giobbe GG, Luni C, Hu Q, Maroni I, Orford MR, et al. The microfluidic environment reveals a hidden role of self-organizing extracellular matrix in hepatic commitment and organoid formation of hiPSCs. Cell Rep. (2020) 33:108453. doi: 10.1016/j.celrep.2020.108453

121. Tao T, Wang Y, Chen W, Li Z, Su W, Guo Y, et al. Engineering human islet organoids from iPSCs using an organ-on-chip platform. Lab Chip. (2019) 19:948-58. doi: 10.1039/C8LC01298A

122. Wang G, McCain ML, Yang L, He A, Agarwal A, Yuan H, et al. Modeling the mitochondrial cardiomyopathy of Barth syndrome with iPSC and heart-onchip technologies. Nat Methods. (2014) 20:616-23. doi: 10.1038/nm.3545

123. Ellis BW, Acun A, Can UI, Zorlutuna P. Human iPSC-derived myocardiumon-chip with capillary-like flow for personalized medicine. Biomicrofluidics. (2017) 11:024105. doi: 10.1063/1.4978468

124. Kasendra M, Luc R, Yin J, Manatakis D V., Kulkarni G, Lucchesi $\mathrm{C}$, et al. Duodenum intestine-chip for preclinical drug assessment in a human relevant model. Elife. (2020) 9:e50135. doi: 10.7554/eLife. 50135

125. Workman MJ, Gleeson JP, Troisi EJ, Estrada HQ, Kerns SJ, Hinojosa $\mathrm{CD}$, et al. Enhanced utilization of induced pluripotent stem cellderived human intestinal organoids using microengineered chips. Cell Mol Gastroenterol Hepatol. (2018) 5:669-77. doi: 10.1016/j.jcmgh.2017. 12.008

126. Nikolaev M, Mitrofanova O, Broguiere N, Geraldo S, Dutta D, Tabata $\mathrm{Y}$, et al. Homeostatic mini-intestines through scaffold-guided organoid morphogenesis. Nature. (2020) 585:574-8. doi: 10.1038/s41586-0202724-8

127. Sidar B, Jenkins BR, Huang S, Spence JR, Walk ST, Wilking JN. LongTerm flow through human intestinal organoids with the gut organoid flow chip (GOFlowChip). Lab Chip. (2019) 19:3552-62. doi: 10.1039/C9LC00 $653 \mathrm{~B}$

128. Lee KK, McCauley HA, Broda TR, Kofron MJ, Wells JM, Hong CI. Human stomach-on-a-chip with luminal flow and peristalticlike motility. Lab Chip. (2018) 18:3079-85. doi: 10.1039/C8LC00 910D

129. Musah S, Mammoto A, Ferrante TC, Jeanty SSF, Hirano-Kobayashi M, Mammoto T, et al. Mature induced-pluripotent-stem-cell-derived human podocytes reconstitute kidney glomerular-capillary-wall function on a chip. Nat Biomed Eng. (2017) 1:0069. doi: 10.1038/s41551-017-0069

130. Lin NYC, Homan KA, Robinson SS, Kolesky DB, Duarte N, Moisan A, et al. Renal reabsorption in 3D vascularized proximal tubule models. Proc Natl Acad Sci USA. (2019) 116:5399-404. doi: 10.1073/pnas.1815208116 
131. Ramme AP, Koenig L, Hasenberg T, Schwenk C, Magauer C, Faust D, et al. Autologous induced pluripotent stem cell-derived four-organ-chip. Fut Sci OA. (2019) 5:FSO413. doi: 10.2144/fsoa-2019-0065

132. Schimek K, Busek M, Brincker S, Groth B, Hoffmann S, Lauster R, et al. Integrating biological vasculature into a multi-organ-chip microsystem. Lab Chip. (2013) 13:3588-98. doi: 10.1039/c3lc50217a

133. Kim J, Chung M, Kim S, Jo DH, Kim JH, Jeon NL. Engineering of a biomimetic pericyte-covered 3D microvascular network. PLOS ONE. (2015) 10:e0133880. doi: 10.1371/journal.pone.0133880

134. Moya ML, Hsu Y-H, Lee AP, Hughes CCW, George SC. In vitro perfused human capillary networks. Tissue Eng Part C Methods. (2013) 19:7307. doi: 10.1089/ten.tec.2012.0430

135. Kim S, Lee H, Chung M, Jeon NL. Engineering of functional, perfusable 3D microvascular networks on a chip. Lab Chip. (2013) 13:1489500. doi: 10.1039/c3lc41320a

136. Chung M, Ahn J, Son K, Kim S, Jeon NL. Biomimetic model of tumor microenvironment on microfluidic platform. Adv Healthc Mater. (2017) 6. doi: 10.1002/adhm.201700196

137. Van Duinen V, Stam W, Mulder E, Famili F, Reijerkerk A, Vulto P, et al. Robust and scalable angiogenesis assay of perfused 3D human iPSC-derived endothelium for anti-angiogenic drug screening. Int J Mol Sci. (2020) 21:4808. doi: 10.3390/ijms21134804

138. Sieber S, Wirth L, Cavak N, Koenigsmark M, Marx U, Lauster R, et al. Bone marrow-on-a-chip: long-term culture of human haematopoietic stem cells in a three-dimensional microfluidic environment. J Tissue Eng Regen Med. (2017) 12:479-89. doi: 10.1002/term.2507

139. Chou DB, Frismantas V, Milton Y, David R, Pop-Damkov P, Ferguson D, et al. Authorcorrection: on-chip recapitulation of clinical bone marrow toxicities and patient-specific pathophysiology. Nat Biomed Eng. (2020) 4:477. doi: 10.1038/s41551-020-0529-6

140. Westein E, Meer AD Van Der, Kuijpers MJE, Frimat J, Berg A Van Den, Heemskerk JWM. Atherosclerotic geometries exacerbate pathological thrombus formation poststenosis in a von Willebrand factor-dependent manner. Proc Natl Acad Sci USA. (2013) 110:1357-62. doi: 10.1073/pnas. 1209905110

141. Miller CP, Shin W, Ahn EH, Kim HJ, Kim D-H. Engineering microphysiological immune system responses on chips. Trends Biotechnol. (2020) 38:857-72. doi: 10.1016/j.tibtech.2020.01.003

142. Guo Y, Luo R, Wang Y, Deng P, Song T. SARS-CoV-2 induced intestinal responses with a biomimetic human gut-on-chip. Sci Bull. (2021) 66:78393. doi: 10.1016/j.scib.2020.11.015

143. Richardson IM, Calo CJ, Hind LE, Lin F. Microphysiological systems for studying cellular crosstalk during the neutrophil response to infection. Front Immunol. (2021) 12:661537. doi: 10.3389/fimmu.2021.661537

144. Laronda MM, Burdette JE, Kim JJ, Woodruff TK. Recreating the female reproductive tract in vitro using iPSC technology in a linked microfluidics environment. Stem Cell Res Ther. (2013) 4(Suppl. 1):S13. doi: $10.1186 /$ scrt374

145. Giese C, Lubitz A, Demmler CD, Reuschel J, Bergner K, Marx U. Immunological substance testing on human lymphatic micro-organoids in vitro. J Biotechnol. (2010) 148:38-45. doi: 10.1016/j.jbiotec.2010.03.001

146. Bauer S, Wennberg Huldt C, Kanebratt KP, Durieux I, Gunne D, Andersson $S$, et al. Functional coupling of human pancreatic islets and liver spheroids on-a-chip: towards a novel human ex vivo type 2 diabetes model. Sci Rep. (2017) 7:14620. doi: 10.1038/s41598-017-14815-w

147. Hoeng J, Bovard D, Peitsch MC, (editors). Organ-on-a-Chip. Academic Press (2020). p. 546. doi: 10.1016/B978-0-12-817202-5.00016-4

148. Jubran A. Pulse oximetry. Crit Care. 19:272. doi: 10.1186/s13054-015-0984-8

149. Lima R, Wada S, Tanaka S, Takeda M, Ishikawa T, Tsubota K, et al. In vitro blood flow in a rectangular PDMS microchannel: experimental observations using a confocal micro-PIV system. Biomed Microdev. (2008) 10:153-67. doi: 10.1007/s10544-007-9121-z

150. Gravina R, Alinia P, Ghasemzadeh H, Fortino G. Multi-sensor fusion in body sensor networks: state-of-the-art and research challenges. Inf Fusion. (2017) 35:68-80. doi: 10.1016/j.inffus.2016.09.005

151. Henry OYF, Villenave R, Cronce M, Leineweber W, Benz M, Ingber DE. Organs-on-chips with integrated electrodes for trans-epithelial electrical resistance (TEER) measurements of human epithelial barrier function. Lab Chip. (2017) 17:2264-71. doi: 10.1039/C7LC00155J

152. van der Helm M, Henry OYF, Bein A, Odijk M, Meer AD Van Der, Eijkel JCT. Non-invasive sensing of transepithelial barrier function and tissue differentiation in organs-on-chips using impedance spectroscopy. Lab Chip. (2019) 19:452-63. doi: 10.1039/C8LC00129D

153. Oleaga C, Lavado A, Riu A, Rothemund S, Carmona-Moran CA, Persaud $\mathrm{K}$, et al. Long-term electrical and mechanical function monitoring of a human-on-a-chip system. Adv Funct Mater. (2019) 29:1805792. doi: 10.1002/adfm.201970049

154. Das S, Gordián-vélez WJ, Ledebur HC, Mourkioti F, Serruya MD, Cullen DK. Innervation: the missing link for biofabricated tissues and organs. NPJ Regen Med. (2020) 5:11. doi: 10.1038/s41536-020-0096-1

155. Sharma AD, Mccoy L, Jacobs E, Willey H, Behn JQ, Nguyen $\mathrm{H}$, et al. Engineering a $3 \mathrm{D}$ functional human peripheral nerve in vitro using the Nerve-on-a-Chip platform. Sci Rep. (2019) 9:8921. doi: 10.1038/s41598-019-45407-5

156. Hyung S, Lee S, Kim J, Kim Y, Kim S, Kim HN, et al. A 3D disease and regeneration model of peripheral nervous system-on-a-chip. Sci Adv. (2021) 7:eabcd9749. doi: 10.1126/sciadv.abd9749

157. Birey F, Andersen J, Makinson CD, Islam S, Wei W, Huber N, et al. Assembly of functionally integrated human forebrain spheroids. Nature. (2017) 545:54-9. doi: 10.1038/nature22330

158. Bagley JA, Reumann D, Bian S, Lévi-strauss J, Knoblich JA. Fused cerebral organoids model interactions between brain regions. Nat Methods. (2017) 14:743-51. doi: 10.1038/nmeth.4304

159. Xiang Y, Tanaka Y, Patterson B, Kang Y, Govindaiah G, Roselaar N, et al. Fusion of regionally-specified hPSC-derived organoids models human brain development and interneuron migration. Cell Stem Cell. (2017) 21:38398.e7. doi: 10.1016/j.stem.2017.07.007

160. Osaki T, Uzel SGM, Kamm RD. Microphysiological 3D model of amyotrophic lateral sclerosis (ALS) from human iPS-derived muscle cells and optogenetic motor neurons. Sci Adv. (2018) 4:eaat5847. doi: 10.1126/sciadv.aat5847

161. Soucy JR, Bindas AJ, Brady R, Torregrosa T, Denoncourt CM, Hosic S, et al. Reconfigurable microphysiological systems for modeling innervation and multitissue interactions. Adv Biosyst. (2020) 4:e2000133. doi: 10.1002/adbi.202000133

162. Martins JF, Fischer C, Urzi A, Spuler S, Sauer S. Self-organizing 3D human trunk neuromuscular organoids. Cell Stem Cell. (2020) 26:17286.e6. doi: 10.1016/j.stem.2019.12.007

163. Cho A-N, Jin Y, Kim S, Kumar S, Shin H, Kang H-C, et al. Aligned brain extracellular matrix promotes differentiation and myelination of human-induced pluripotent stem cell-derived oligodendrocytes. ACS Appl Mater Interfaces. (2019) 11:15344-53. doi: 10.1021/acsami.9b0 3242

164. Spijkers XM, Vuhman SP, Dorleijn JC, Vulto P, Wevers NR, Pasterkamp RJ. A directional 3D neurite outgrowth model for studying motor axon biology and disease. Sci Rep. (2021) 11:2080. doi: 10.1038/s41598-021-81 $335-\mathrm{z}$

165. Goverse G, Stakenborg M, Matteoli G. The intestinal cholinergic antiinflammatory pathway. J Physiol. (2016) 594:5771-80. doi: 10.1113/JP27 1537

166. Jung W, Levesque J, Ruitenberg MJ. It takes nerve to fight back: the significance of neural innervation of the bone marrow and spleen for immune function. Semin Cell Dev Biol. (2016) 61:60-70. doi: 10.1016/j.semcdb.2016.08.010

167. Gilbert JA, Blaser MJ, Caporaso JG, Jansson JK, Lynch SV, Knight R. Current understanding of the human microbiome. Nat Med. (2018) 24:392400. doi: $10.1038 / \mathrm{nm} .4517$

168. Ceppa FA, Izzo L, Sardelli L, Raimondi I, Tunesi M, Albani D, et al. Human gut-microbiota interaction in neurodegenerative disorders and current engineered tools for its modeling. Front Cell Infect Microbiol. (2020) 10:297. doi: 10.3389/fcimb.2020.00297

169. Raimondi MT, Albani D, Giordano C. An organ-on-a-chip engineered platform to study the microbiota-gut-brain axis in neurodegeneration. Trends Mol Med. (2019) 25:737-40. doi: 10.1016/j.molmed.2019. 07.006 
170. Miller PG, Shuler ML. Design and demonstration of a pumpless 14 compartment microphysiological system. Biotechnol Bioeng. (2016) 113:2213-27. doi: 10.1002/bit.25989

171. Edington CD, Li W, Chen K, Geishecker E, Kassis T, Soenksen LR. Interconnected microphysiological systems for quantitative biology and pharmacology studies. Sci Rep. (2018) 8:4530. doi: 10.1038/s41598-018-22749-0

172. Ramezankhani R, Torabi S, Minaei N, Madani H, Rezaeiani S, Hassani $\mathrm{SN}$, et al. Two decades of global progress in authorized advanced therapy medicinal products: an emerging revolution in therapeutic strategies. Front Cell Dev Biol. (2020) 8:547653. doi: 10.3389/fcell.2020.547653

173. Makurvet FD. Biologics vs. small molecules: drug costs and patient access. Med Drug Discov. (2021) 9:100075. doi: 10.1016/j.medidd.2020.100075

174. Hernandez I, Bott SW, Patel AS, Wolf CG, Hospodar AR, Sampathkumar $\mathrm{S}$, et al. Pricing of monoclonal antibody therapies: higher if used for cancer? Am J Manag Care. (2018) 24:109-12.

175. Ronco V, Dilecce M, Lanati E, Canonico PL, Jommi C. Price and reimbursement of advanced therapeutic medicinal products in Europe: are assessment and appraisal diverging from expert recommendations? J Pharm Policy Pract. (2021) 14:30. doi: 10.1186/s40545-021-00 311-0

176. Nair R, Westin J. CAR T-cells. Adv Exp Med Biol. (2020) 1244:21533. doi: 10.1007/978-3-030-41008-7_10

177. Sesques P, Ferrant E, Safar V, Wallet F, Tordo J, Dhomps A, et al. Commercial anti-CD19 CAR $\mathrm{T}$ cell therapy for patients with relapsed/refractory aggressive B cell lymphoma in a European center. Am J Hematol. (2020) 95:1324-33. doi: 10.1002/ajh.25951

178. Roemhild A, Otto NM, Moll G, Abou-El-Enein M, Kaiser $D$, Bold $G$, et al. Regulatory $T$ cells for minimising immune suppression in kidney transplantation: phase I/IIa clinical trial. BMJ. (2020) 371:m3734. doi: 10.1136/bmj. $\mathrm{m} 3734$
179. Lambert J. Growth and Resilience in Regenerative Medicine Annual Report. Alliance for Regenerative Medicine (2020). Available online at: http:// alliancerm.org/wp-content/uploads/2021/03/ARM_AR2020_FINAL-PDF. pdf

180. Zheng PP, Kros JM, Li J. Approved CAR T cell therapies: ice bucket challenges on glaring safety risks and long-term impacts. Drug Discov Today. (2018) 23:1175-82. doi: 10.1016/j.drudis.2018. 02.012

Conflict of Interest: UM is a founder, shareholder, and the CSO of TissUse GmbH, an organ-on-a-chip company dealing with MPS-based biological models. RL is a shareholder of TissUse GmbH. APR, AW, EA, HE, LK, and E-MD are employed by TissUse.

The remaining authors declare that the research was conducted in the absence of any commercial or financial relationships that could be construed as a potential conflict of interest.

Publisher's Note: All claims expressed in this article are solely those of the authors and do not necessarily represent those of their affiliated organizations, or those of the publisher, the editors and the reviewers. Any product that may be evaluated in this article, or claim that may be made by its manufacturer, is not guaranteed or endorsed by the publisher.

Copyright (C) 2021 Marx, Accastelli, David, Erfurth, Koenig, Lauster, Ramme, Reinke, Volk, Winter and Dehne. This is an open-access article distributed under the terms of the Creative Commons Attribution License (CC BY). The use, distribution or reproduction in other forums is permitted, provided the original author(s) and the copyright owner(s) are credited and that the original publication in this journal is cited, in accordance with accepted academic practice. No use, distribution or reproduction is permitted which does not comply with these terms. 